\title{
Numerical investigation of spudcan penetration in multi-layer deposits with an interbedded sand layer
}

\author{
J. ZHENG*, M. S. HOSSAIN* and D. WANG $\dagger$
}

\begin{abstract}
For calculating spudcan penetration resistance in an interbedded sand layer between two clay layers, the recently developed mechanism-based design methods for surface sand-over-clay deposits are extended to account for the influence of the overlying clay layer. A series of large-deformation finite-element (LDFE) analyses were carried out, varying layer geometries and strength parameters. The numerical results and existing centrifuge test data are used to calibrate the extended design methods. The performance of the modified design methods and those suggested in the ISO standard 19905-1 is compared, confirming the accuracy of the former methods in estimating the peak penetration resistance in the sand layer. LDFE analyses were also carried out adding a strong fourth layer, with the corresponding effects on the increasing peak resistance in the second (sand) layer and squeezing behaviour (or limiting squeezing depth) in the third (soft clay) layer discussed. Design formulas are also developed to estimate the increase of peak resistance and limiting squeezing depth due to the presence of the strong fourth layer.
\end{abstract}

KEYWORDS: clays; failure; footings/foundations; numerical modelling; offshore engineering; sands

\section{INTRODUCTION}

For spudcan penetration in a sand-over-clay soil layering system, a reduction in penetration resistance may occur, forming a local peak in the sand layer. When the applied preload exceeds the local peak bearing capacity, leg plunge occurs until the peak resistance is re-established again in the underlying layers. This is termed as 'punch-through' failure, implying a rapid rate of penetration. New mechanism-based design methods (Lee et al., 2013a, 2013b; Hu et al., 2014a, 2014b, 2015) have recently been proposed for estimating the peak bearing capacity in the surface sand layer and the bearing capacity in the underlying clay layer. However, their applicability in multi-layer soils with an overlying clay layer (i.e. clay-sand-clay deposit) is yet to be examined. This study focuses on spudcan penetration in an interbedded sand-over-clay layering system through large-deformation finite-element (LDFE) analyses, together with centrifuge test data reported by Hossain (2014). Additional analyses were carried out adding a stiff bottom layer (i.e. in a soft clay-sand-soft clay-stiff clay deposit) to quantify the corresponding effects on the magnitude of the peak penetration resistance in the second (sand) layer and the severity of punch-through. The aim is to extend the existing design methods for two-layer sand-over-clay deposits to be applicable for assessing spudcan penetration in three- (weakstrong-weak) and four-layer (weak-strong-weak-strong) seabed profiles within the depth of interest.

Manuscript received 25 April 2016; revised manuscript accepted 17 January 2017. Published online ahead of print 17 March 2017. Discussion on this paper closes on 1 May 2018, for further details see p. ii.

* Centre for Offshore Foundation Systems (COFS), The University of Western Australia, Crawley, WA, Australia.

$\uparrow$ Shandong Provincial Key Laboratory of Marine Environment and Geological Engineering (Former, Centre for Offshore Foundation Systems, The University of Western Australia), Ocean University of China, Qingdao, P. R. China.

\section{DESIGN METHODS}

Existing design methods for sand-over-clay: punch-through

For assessing spudcan penetration resistance in a sandover-clay layering system, four existing design methods are compared in this study, including: (a) load spread method; (b) punching shear method; (c) the method by Lee et al. (2013a, 2013b), referred to herein as the 'Lee et al. method'; and $(d)$ the method by $\mathrm{Hu}$ et al., (2014a, 2014b, 2015), referred to herein as the 'Hu et al. method'. The first two methods are recommended in the current design guidelines ISO standard 19905-1 (ISO, 2012) - while the other two were proposed recently. The corresponding design formulas and parameters are summarised in Table 1.

The load spread and punching shear methods (ISO methods; ISO, 2012) were proposed based on the conceptual models in Fig. 1. The design formulas are given for the gross penetration resistance $q_{\mathrm{v}}$ with no soil backfill, which is calculated from the total penetration resistance $q_{\mathrm{u}}$ as

$$
q_{\mathrm{v}}=q_{\mathrm{u}}-\gamma^{\prime} \frac{V_{\mathrm{sp}}}{A}+\gamma^{\prime} \max \left(d-H_{\mathrm{cav}}, 0\right)
$$

where $\gamma^{\prime}$ is the effective unit weight of the soil; $V_{\mathrm{sp}}$ is the volume of the embedded spudcan including shaft; $A$ is the largest plan area of the spudcan; $d$ is the penetration depth of the spudcan at the largest cross-section; and $H_{\text {cav }}$ is the depth of cavity above the spudcan, which is suggested to be calculated according to Hossain \& Randolph (2009b).

Based on the observed soil failure mechanisms during continuous penetration of spudcan foundations in surface sand-over-clay deposits (Teh et al., 2008), Lee et al. (2013b) extended the punching shear model assuming inclined shear planes and the peak resistance at the surface of the sand layer (the Lee et al. method). Instead of punching shear coefficient $K_{\mathrm{s}}$, a distribution factor $D_{\mathrm{F}}$ was introduced, which estimates the pressure on the shear plane from the mean vertical effective stress within the sand plug.

The Lee et al. method was developed through calibration against the centrifuge test data on dense sand-over-clay. $\mathrm{Hu}$ et al. (2014a) performed centrifuge tests for spudcan penetration in medium dense sand-over-clay, and improved 
Table 1. Design formulas for assessing spudcan penetration resistance in sand-over-clay

\begin{tabular}{|c|c|c|c|c|c|}
\hline \multirow[t]{2}{*}{ Method } & \multicolumn{3}{|l|}{ Sand layer } & \multirow[t]{2}{*}{ Clay layer } & \multirow[t]{2}{*}{ Notes } \\
\hline & Design formula & \multicolumn{2}{|l|}{ Parameters $\dagger$} & & \\
\hline $\begin{array}{l}\text { Load } \\
\text { spread } \\
\text { method } \\
\text { Punching } \\
\text { shear } \\
\text { method }\end{array}$ & $\begin{array}{l}q_{\mathrm{v}}=\left(N_{\mathrm{c}, \text { int }} s_{\mathrm{ub}}+p_{0}^{\prime}\right) 0 \cdot 25 \pi\left(D+2 \frac{T}{n_{\mathrm{s}}}\right)^{2} / A \\
q_{\mathrm{v}}=\left(N_{\mathrm{c}, \text { int } s_{\mathrm{ub}}}+p_{0}^{\prime}\right)+\frac{2 T}{D}\left(\gamma_{\mathrm{s}}^{\prime} T+2 p_{0}^{\prime}\right) K_{\mathrm{s}} \tan \phi^{\prime}\end{array}$ & \multicolumn{2}{|c|}{$\begin{array}{l}n_{\mathrm{s}} \text { has a range of } 3 \sim 5 \text {. In this study } n_{\mathrm{s}}=3 \text { is adopted } \\
\text { A design chart is provided by ISO (2012) for the value of } \\
K_{\mathrm{s}} \text { following Hanna \& Meyerhof }(1980) \text {. In this study, } \\
\text { the formula suggested by InSafeJIP (2011), which is } \\
\text { derived from Hanna \& Meyerhof (1980) chart, is used: } \\
K_{\mathrm{s}} \tan \phi^{\prime}=2 \cdot 5\left(s_{\mathrm{ubs}} / \gamma_{\mathrm{s}}^{\prime} D\right)^{0.6} \\
\text { where } s_{\mathrm{ubs}} \text { is the undrained shear strength at the sand-clay } \\
\text { interface }\end{array}$} & $q_{\mathrm{v}}=N_{\mathrm{c}} s_{\mathrm{ub}}+p_{0}^{\prime}$ & $\begin{array}{l}\text { - Recommended in } \\
\text { ISO (2012) } \\
\text { - } N_{\mathrm{c}} \text { and } N_{\mathrm{c}, \text { int }} \text { are } \\
\text { bearing capacity } \\
\text { factors calculated } \\
\text { following } \\
\text { Skempton (1951) } \\
\text { - For non-uniform } \\
\text { clay, } s_{\mathrm{ub}} \text { is taken } \\
\text { as the average } \\
\text { shear strength } \\
\text { over a depth of } \\
D / 2 \text { below layer } \\
\text { interface or } \\
\text { spudcan base }\end{array}$ \\
\hline $\begin{array}{l}\text { Lee } e t \text { al. } \\
\text { method }\end{array}$ & $\begin{aligned} q_{\text {peak }}= & \left(N_{\mathrm{c}, \text { int }} s_{\mathrm{u}, \text { int }}+q_{0}\right)\left(1+\frac{2 H_{\mathrm{s}}}{D} \tan \psi\right)^{L}+\frac{\gamma_{\mathrm{s}}^{\prime} D}{2\left(E^{*}+1\right) \tan \psi} \\
& \times\left[1-\left(1-\frac{2 H_{\mathrm{s}}}{D} E^{*} \tan \psi\right)\left(1+\frac{2 H_{\mathrm{s}}}{D} \tan \psi\right)^{E^{*}}\right]\end{aligned}$ & $\begin{array}{l}E^{*}=2\left[1+D_{\mathrm{F}}\left(\frac{\tan \phi^{*}}{\tan \psi}-1\right)\right] \\
\tan \phi^{*}=\frac{\sin \phi^{\prime} \cos \psi}{1-\sin \phi^{\prime} \sin \psi}\end{array}$ & $\begin{array}{l}D_{\mathrm{F}}=1.333-0.889 \frac{H_{\mathrm{s}}}{D} \\
\frac{H_{\mathrm{s}}}{D}<0.9\end{array}$ & $q_{\mathrm{u}}=\left(14 \frac{H_{\mathrm{s}}}{D}+9 \cdot 5\right) s_{\mathrm{u} 0}$ & $\begin{array}{l}\text { Peak resistance } \\
\text { depth is } 0 \cdot 05 H_{\mathrm{s}} \\
\text { below the sand } \\
\text { layer surface for } \\
\text { spudcans } \\
\text { - } N_{\mathrm{c}, \text { int }} \text { is } \\
\text { calculated } \\
\text { following } \\
\text { Houlsby \& } \\
\text { Martin }(2003)\end{array}$ \\
\hline $\begin{array}{l}\text { Hu et al. } \\
\text { method }\end{array}$ & $\begin{aligned} q_{\text {peak }}= & \left(N_{\mathrm{c}, \text { int }} s_{\mathrm{u}, \text { int }}+q_{0}+0 \cdot 12 \gamma_{\mathrm{s}}^{\prime} H_{\mathrm{s}}\right)\left(1+\frac{1 \cdot 76 H_{\mathrm{s}}}{D} \tan \psi\right)^{E^{*}}+\frac{\gamma_{\mathrm{s}}^{\prime} D}{2\left(E^{*}+1\right) \tan \psi} \\
& \times\left[1-\left(1-\frac{1 \cdot 76 H_{\mathrm{s}}}{D} E^{*} \tan \psi\right)\left(1+\frac{1 \cdot 76 H_{\mathrm{s}}}{D} \tan \psi\right)^{E^{*}}\right]\end{aligned}$ & $\begin{array}{l}\phi^{\prime}=\phi_{\text {crit }}^{\prime}+2 \cdot 65 I_{\mathrm{R}} \\
0 \cdot 8 \psi=\phi^{\prime}-\phi_{\text {crit }}^{\prime} \\
\left\{\begin{array}{l}I_{\mathrm{R}}=I_{\mathrm{D}}\left(Q-\ln q_{\text {peak }}\right)-1 \\
0<I_{\mathrm{R}}<4\end{array}\right.\end{array}$ & $\begin{array}{l}D_{\mathrm{F}}=0.642\left(\frac{H_{\mathrm{s}}}{D}\right)^{-0.576} \\
0.16 \leq \frac{H_{\mathrm{s}}}{D} \leq 1.0\end{array}$ & $\begin{aligned} q_{\mathrm{u}}= & \left(11 \frac{H_{\mathrm{s}}}{D}+10 \cdot 5\right) s_{\mathrm{u} 0} \\
& +0 \cdot 9 H_{\mathrm{s}} \gamma_{\mathrm{c}}^{\prime}\end{aligned}$ & $\begin{array}{l}\text { Peak resistance } \\
\text { depth is } 0 \cdot 12 H_{\mathrm{s}} \\
\text { below the sand } \\
\text { layer surface } \\
N_{\mathrm{c}, \text { int }} \text { is } \\
\text { calculated } \\
\text { following } \\
\text { Houlsby \& } \\
\text { Martin }(2003)\end{array}$ \\
\hline
\end{tabular}

$\uparrow$ The other parameters are defined under the notation section. 


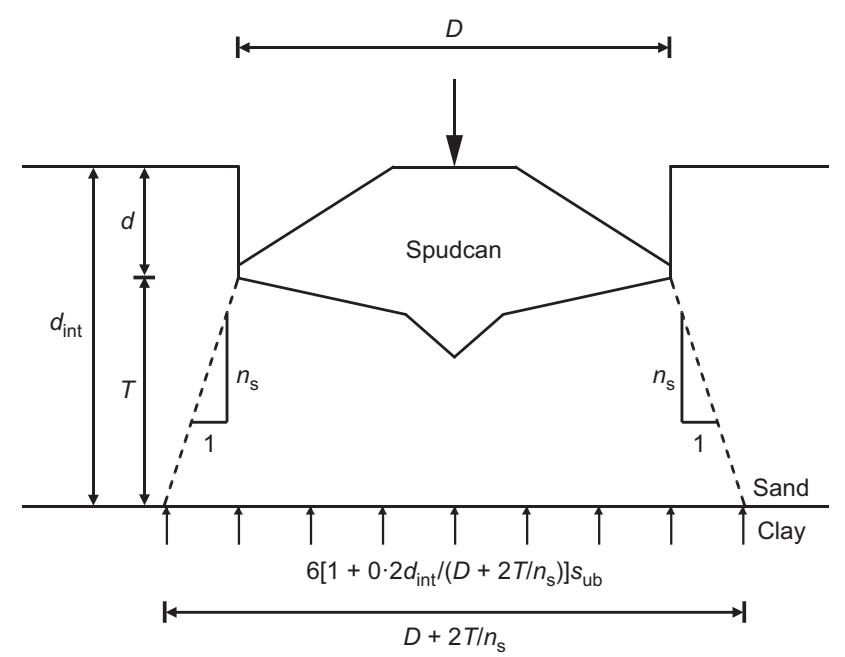

(a)

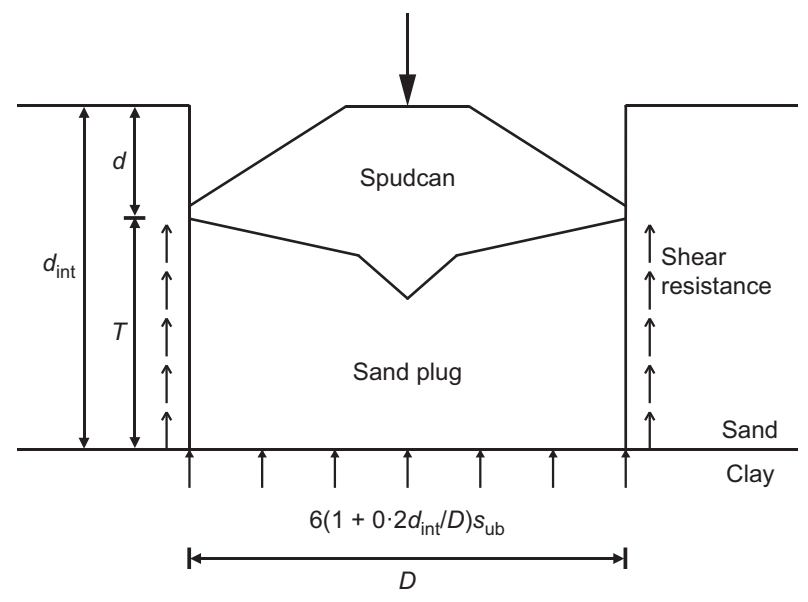

(b)

Fig. 1. Conceptual models for calculating spudcan penetration resistance in sand layer overlying clay: (a) load spread model; (b) punching shear model

the design formulas of the Lee et al. method assuming the peak resistance at a depth of $0 \cdot 12 H_{\mathrm{s}}$ below the sand surface. A new expression for $D_{\mathrm{F}}$ was proposed by covering a wider range of centrifuge test data.

\section{Existing design method for soft clay-over-strong layer: squeezing}

For spudcan penetration in a clay layer of undrained shear strength $s_{\mathrm{u}}$ overlying a stronger layer, the penetration resistance due to squeezing is calculated as (Meyerhof \& Chaplin, 1953; also adopted in ISO 19905-1 (ISO, 2012))

$$
q_{\mathrm{v}}=\operatorname{Max}\left[\left(N_{\mathrm{c}}+\frac{D}{3 T}-1\right) s_{\mathrm{u}}, N_{\mathrm{c}} s_{\mathrm{u}}\right]+p_{0}^{\prime} \quad \text { for } T \leq h_{\mathrm{sq}}
$$

The penetration resistance calculated by equation (2) should be limited by that at the surface of the underlying stronger layer. The limiting squeezing depth $h_{\mathrm{sq}}-$ the depth range within which squeezing comes into effect and the penetration resistance increases sharply - is suggested by ISO (2012) as

$$
\frac{h_{\mathrm{sq}}}{D}=\frac{T}{D}=\frac{1}{3 \cdot 45[1+1 \cdot 025(d / D)]}
$$

Existing design method for multi-layer soils

For the complete penetration resistance profile in a multi-layer deposit, the bottom-up approach suggested by ISO (2012) can be used, combining design methods for punch-through and squeezing. First, the bearing capacity of a spudcan on the top of the lowest two layers is computed. These two layers are then treated as one (lower) layer in a subsequent two-layer system analysis involving the immediate upper layer.

\section{Extended mechanism-based design methods for soft clay-sand-soft to moderate clay-(strong layer): squeezing, punch-through, (squeezing)}

For the application in an interbedded sand-over-clay layering system, for example, a clay-sand-clay deposit, it is proposed in this study that the Lee et al. and $\mathrm{Hu}$ et al. methods are extended by taking the surcharge $q_{0}$ (see Table 1) equal to the overburden stress of the clay layer that overlies the sand layer. Once the peak resistance $q_{\text {peak }}$ in the sand layer is calculated, $q_{\mathrm{u}}$ is estimated by taking away the submerged weight of the soils on top of the spudcan, that is, $q_{\mathrm{u}}=q_{\text {peak }}-\gamma^{\prime} \max \left(d-H_{\text {cav }}, 0\right)$.

For assessing spudcan penetration in soft clay-sand-soft to moderate clay-stiff clay deposits, two influences should be accounted for: (a) the influence of the fourth (strong) layer (within a sensible distance) on the peak resistance in the second (sand) layer; $(b)$ the influence of the trapped soil plug at the base of the advancing spudcan from the upper layers on the squeezing depth while approaching the fourth (strong) layer. Formulas are proposed to extend the ISO methods and the Lee et al. and $\mathrm{Hu}$ et al. methods to account for the former. An iterative approach is proposed to incorporate the effect of the evolving soil plug in estimating the limiting squeezing depth.

\section{NUMERICAL MODEL}

Geometry and parameters

This study has considered a circular spudcan penetrating into a clay-sand-clay deposit with and without a fourth layer of stiff clay, as illustrated schematically in Fig. 2, where the second layer sand with effective unit weight $\gamma_{2}^{\prime}=\gamma_{\mathrm{s}}^{\prime}$ has a thickness of $t_{2}=H_{\mathrm{s}}$ and a relative density $I_{\mathrm{D}}$. Non-uniform undrained shear strengths were considered for the first and third clay layers as $s_{\mathrm{u} 1}=s_{\mathrm{u} 1 \mathrm{~s}}+k_{1} z$ and $s_{\mathrm{u} 3}=s_{\mathrm{u} 3 \mathrm{~s}}+k_{3}\left(z-t_{1}-t_{2}\right)$, respectively, with layer thicknesses of $t_{1}$ and $t_{3}$ (if there was a fourth layer, otherwise infinite), and effective unit weights of $\gamma_{1}^{\prime}$ and $\gamma_{3}^{\prime}$. The fourth (stiff clay) layer had a uniform undrained shear strength $s_{\mathrm{u} 4}$, effective unit weight $\gamma_{4}^{\prime}$ and (nominally) infinite depth. Analyses were undertaken for a spudcan with a $13^{\circ}$ shallow conical underside profile (included angle of $154^{\circ}$ ) and a $76^{\circ}$ protruding spigot of height $0 \cdot 14 D$.

Parametric studies were performed simulating continuous penetration of the spudcan from the seabed, with the selected parameters summarised in Table 2. For convenience, the effective unit weight of the clay layers was considered to be constant and was taken as $\gamma^{\prime}=8 \mathrm{kN} / \mathrm{m}^{3}$, while that of the sand layer was selected as $\gamma_{\mathrm{s}}^{\prime}=10$ and $11 \mathrm{kN} / \mathrm{m}^{3}$ for $I_{\mathrm{D}}=45$ and $90 \%$, respectively.

\section{Analysis details and model set-up}

The LDFE analyses were performed using the coupled Eulerian-Lagrangian (CEL) approach in the commercial FE package Abaqus/Explicit (Dassault Systèmes, 2010). Current CEL function is available only for three-dimensional elements. Only a quarter sector of the domain was involved, accounting for the inherent symmetry, as shown in Fig. 3. 

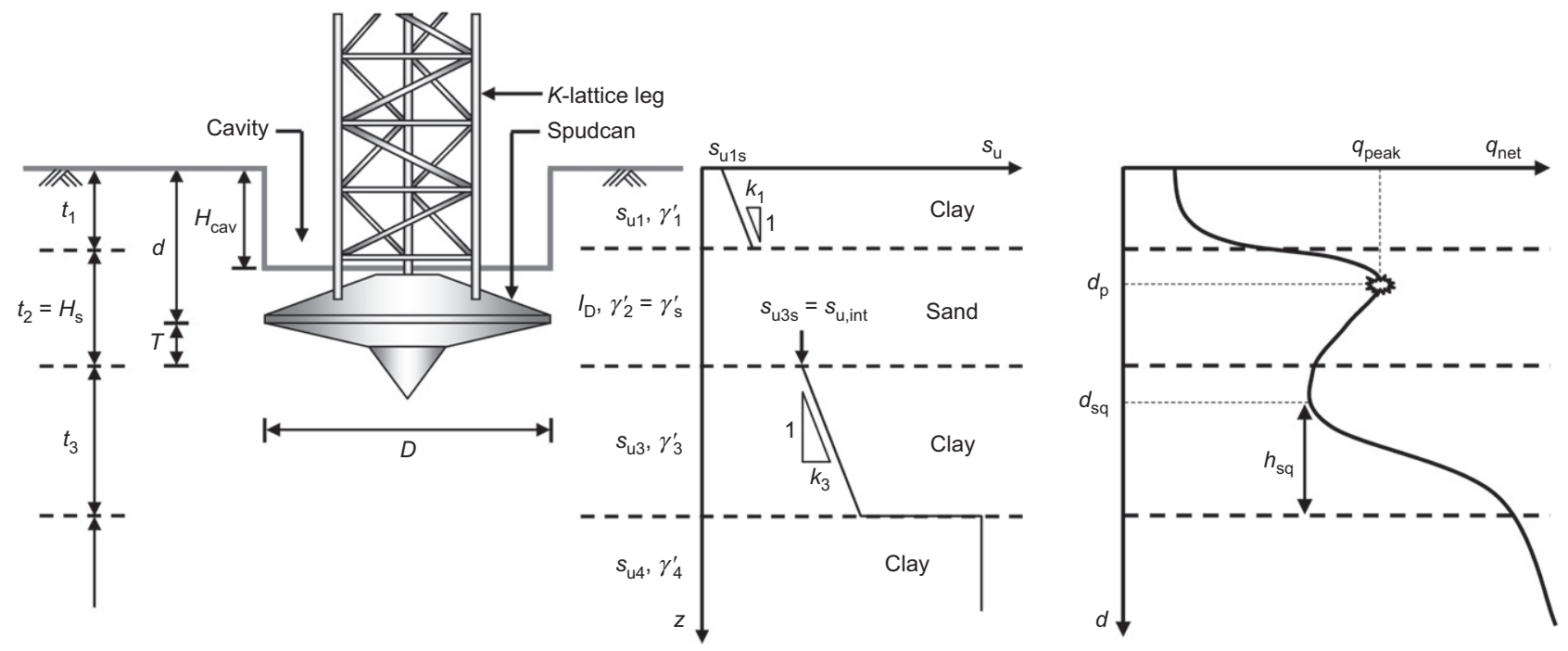

Fig. 2. Schematic diagram of embedded spudcan foundation showing idealised open cavity and corresponding penetration resistance profile

Table 2. Summary of parametric LDFE analyses performed in this study

\begin{tabular}{l|l|l|l|l|l|l|l|l}
\hline \multicolumn{2}{l|}{ First-layer soft clay } & \multicolumn{2}{l|}{ Second-layer sand } & \multicolumn{2}{l|}{ Third-layer soft clay } & Fourth-layer stiff clay \\
\hline $\begin{array}{l}S_{\mathrm{u} 1 \mathrm{~s}}: \\
\mathrm{kPa}\end{array}$ & $k_{1}: \mathrm{kPa} / \mathrm{m}$ & $t_{1} / D$ & $I_{\mathrm{D}}: \%$ & $t_{2} / D\left(H_{\mathrm{s}} / D\right)$ & $s_{\mathrm{u} 3 \mathrm{~s}}: \mathrm{kPa}$ & $k_{3}: \mathrm{kPa} / \mathrm{m}$ & $t_{3} / D$ & $s_{\mathrm{u} 4}: \mathrm{kPa}$ \\
\hline 5 & 1 & $\begin{array}{c}0 \cdot 5,1 \cdot 0 \\
\text { and } 1 \cdot 5\end{array}$ & $\begin{array}{c}45 \text { and } \\
90\end{array}$ & $\begin{array}{c}0 \cdot 25,0 \cdot 33,0 \cdot 42,0 \cdot 5, \\
0 \cdot 58,0 \cdot 66,0 \cdot 75 \text { and } 1\end{array}$ & $\begin{array}{c}7 \cdot 5,15 \\
\text { and } 30\end{array}$ & 1,2 and 3 & $\begin{array}{c}0 \cdot 25,0 \cdot 5,0 \cdot 75, \\
1 \cdot 0,1 \cdot 5 \text { and } \infty\end{array}$ & 100 \\
\hline
\end{tabular}

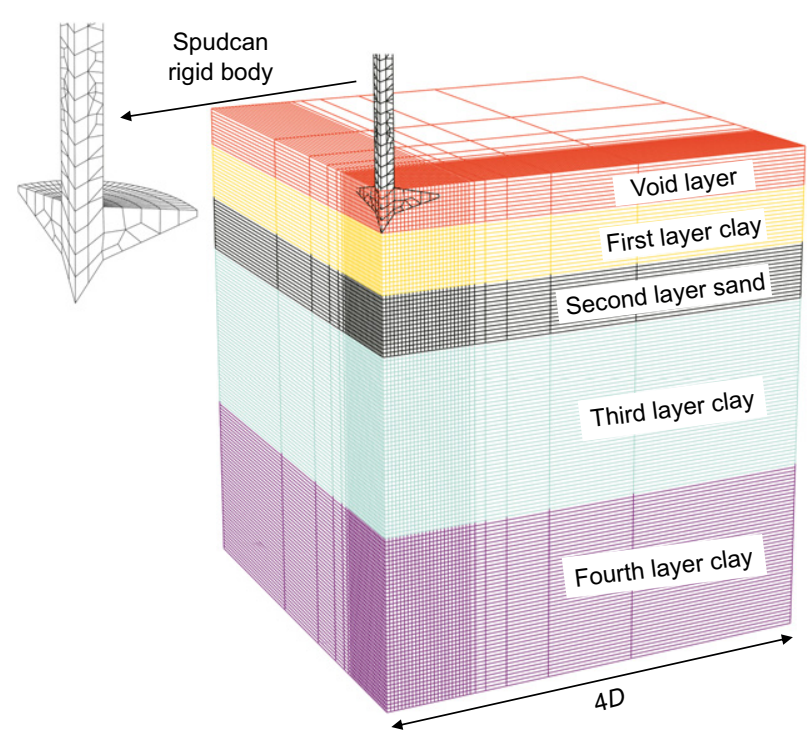

Fig. 3. Numerical model used in parametric study

The spudcan was modelled as a rigid Lagrangian body. During spudcan penetration in a clay-sand-clay profile, the spudcan base was always wrapped by the first-layer clay, as evidenced from centrifuge model tests (Hossain, 2014). This trapping of soft soil was captured by considering the clayspudcan interface as fully rough. A frictional contact was also defined for the sand-spudcan interaction based on the Coulomb friction model with the coefficient of friction $=0.5$. These contact properties were selected in order to maintain the first-layer clay as part of the trapped soil plug. The soil plug plays a major role in developing the penetration resistance. In addition, the frictional resistance between soil-spudcan interactions that depends on the relative roughness of the spudcan base has been found to have minimal influence on the spudcan penetration resistance in layered soil profiles (Hossain \& Randolph, 2010; Hu et al., 2014b).

The soil was discretised using Eulerian elements. The Eulerian mesh included the original soil domain and an overlying layer initially filled with 'void' material to accommodate the soil heave that resulted from the spudcan penetration. A cuboid of fine mesh was created along the trajectory of the spudcan, with a constant element size of $0.025 \mathrm{D}$. Hu et al. (2014b) and $\mathrm{Hu}$ et al. (2015), who used the same constitutive model for sand (discussed later), undertook an extensive mesh-sensitivity study and suggested this element size of $0.025 D$ to achieve adequate numerical accuracy and efficiency. The penetration velocity of the spudcan in the numerical analysis was taken as $0 \cdot 1 \mathrm{~m} / \mathrm{s}$. It was testified as sufficiently slow to avoid inertial effect. This is consistent with the conclusions drawn by Qiu \& Henke (2011), Tho et al. (2012) and Zheng et al. (2015a, 2015b), who adopted a penetration velocity of $0 \cdot 5,0 \cdot 1672$ and $0 \cdot 1 \mathrm{~m} / \mathrm{s}$, respectively.

\section{Constitutive law and material properties}

Clay layer. All clay layers were modelled as an elastoplastic material obeying a Tresca yield criterion, but extended to capture strain rate and strain softening effects. The incorporation of strain rate dependency minimises the effect of mesh dependency caused by softening materials. The soil model follows Einav \& Randolph (2005) and is expressed as

$$
\begin{aligned}
s_{\mathrm{uc}}= & {\left[1+\mu \log \left(\frac{\operatorname{Max}\left(|\dot{\gamma}|, \dot{\gamma}_{\text {ref }}\right)}{\dot{\gamma}_{\text {ref }}}\right)\right] } \\
& \times\left[\delta_{\text {rem }}+\left(1-\delta_{\text {rem }}\right) \mathrm{e}^{-3 \xi / \xi_{95}}\right] s_{\mathrm{u}}
\end{aligned}
$$

where $s_{\mathrm{uc}}$ is the current undrained shear strength considering strain softening and rate dependency. 
The first bracketed term augments the strength according to the maximum shear strain rate $\dot{\gamma}$ relative to a reference value, $\dot{\gamma}_{\text {ref }}$, which was selected for the parametric study so that the normalised spudcan penetration rate $v /\left(D \dot{\gamma}_{\text {ref }}\right)=11 \cdot 11$ (Hossain \& Randolph, 2009a; Hossain et al., 2014). The augment of shear strength follows a logarithmic law with rate parameter $\mu$ taken as $0 \cdot 1$ for circular spudcan foundations (Low et al., 2008).

The second part of equation (4) models the degradation of strength according to an exponential function of the accumulated absolute plastic shear strain, $\xi$, from the intact condition to a fully remoulded ratio, $\delta_{\text {rem }}\left(=1 / S_{\text {t }}\right.$, i.e. inverse of sensitivity, $S_{\mathrm{t}}$ ). A value of $S_{\mathrm{t}}=2.8$ was adopted for the parametric study to be consistent with the sensitivity of the kaolin clay used in the centrifuge tests conducted by Hossain et al. (2011) and Hossain (2014). The value also falls within the typical range of sensitivity of marine clays where jack-up rigs are being used, for example, $S_{\mathrm{t}}=2 \sim 3.5$ for the Gulf of Mexico (Menzies \& Roper, 2008). The relative ductility is controlled by the parameter, $\xi_{95}$, which represents the cumulative shear strain required for $95 \%$ remoulding. A typical value of $\xi_{95}=12$ (i.e. $1200 \%$ shear strain) was used as a similar value was adopted by Zhou \& Randolph (2009), Wang et al. (2010), Hossain et al. (2014) and Dutta et al. (2015) in the simulations of centrifuge tests and case histories, with good agreement obtained between the computed and measured data. This value also falls within the typical range of 10 25 as suggested by Randolph (2004) through matching degradation curves from cyclic penetration and extraction tests on T-bar and ball penetrometers. The sensitivity analyses in terms of the influences of the values of $\mu, S_{\mathrm{t}}$, and $\xi_{95}$ on spudcan penetration resistance were reported by Hossain \& Randolph (2009a).

A uniform stiffness ratio of $E / s_{\mathrm{uc}}=200$ (where $E$ is the Young's modulus) was taken for the clay layers. Considering the relatively fast penetration of spudcans in the field, all the analyses simulated undrained conditions in clay layers, with Poisson's ratio of $0 \cdot 49$. The geostatic stress conditions were modelled using $K_{0}=1$.

Sand layer. Sands exhibit strain hardening or softening response when sheared. The stress-strain response is affected by the initial relative density of the sand and the stress level during shearing. This study has simulated spudcan penetration in medium dense to dense sands of $I_{\mathrm{D}}=44 \sim 90 \%$. The mean stress in the sand during spudcan penetration is mostly less than $150 \mathrm{kPa}$ (White et al., 2008; Hu et al., 2015). Compared with the stress-strain response from laboratory element tests, which were conducted on sand samples with a similar combination of relative density and stress level, the sand in this study was described using a modified Mohr-Coulomb model allowing post-peak softening by varying friction and dilation angles linearly, as shown in Fig. 4, where the subscripts i, p and crit represent initial, peak and critical state values, respectively. In Fig. $4, \varepsilon^{\mathrm{ep}}$ is the accumulated equivalent plastic strain calculated as $\varepsilon^{\mathrm{ep}}=\sum\left(2 / 3 \Delta \boldsymbol{e}_{i j}^{\mathrm{p}} \Delta \boldsymbol{e}_{i j}^{\mathrm{p}}\right)^{1 / 2}$, where $\Delta \boldsymbol{e}_{i j}^{\mathrm{p}}$ is the incremental deviatoric plastic strain tensor. Similar sand models have been adopted by Potts et al. (1990, 1997), Anastasopoulos et al. (2007), Yapage et al. (2015) and Hu et al. (2015).

The threshold shear strains were taken as $\varepsilon_{\mathrm{p}}^{\mathrm{ep}}=4 \%$ and $\varepsilon_{\text {crit }}^{\mathrm{ep}}=10 \%$, as observed broadly in triaxial compression tests on silica sand by Pucker et al. (2013) and as adopted by $\mathrm{Hu}$ et al. (2015). The critical friction angle was taken as $34^{\circ}$ (Cheong, 2002; O’Loughlin \& Lehane, 2003; Hossain, 2014), while the initial and peak friction angles were selected based on the theories as follows. For axisymmetric triaxial

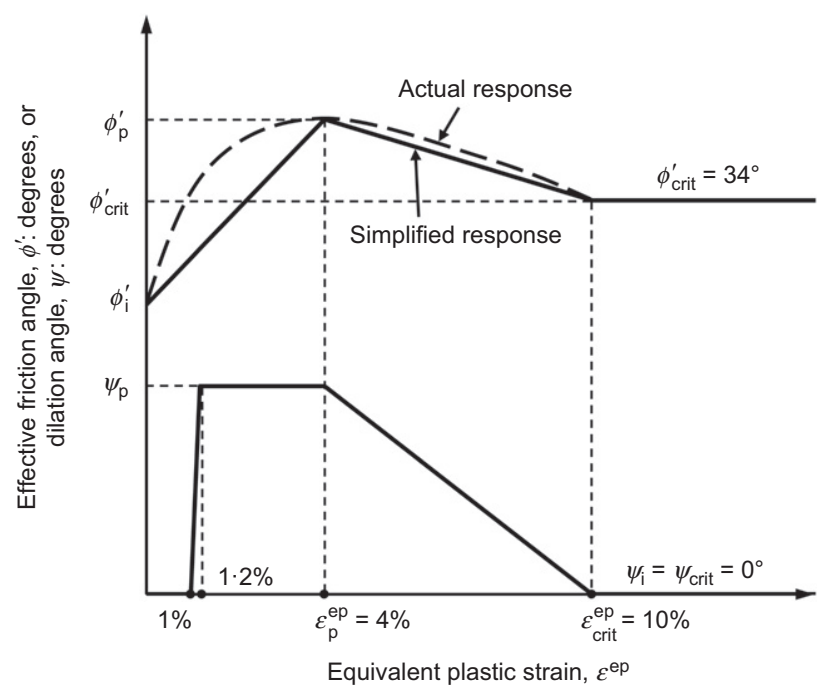

Fig. 4. Variation of friction and dilation angles of modified MohrCoulomb model

compression condition, the deviatoric stress $q=\left(\sigma_{1}^{\prime}-\sigma_{3}^{\prime}\right)$ and the mean effective stress $p^{\prime}=\left(\sigma_{1}^{\prime}+2 \sigma_{3}^{\prime}\right) / 3$, where $\sigma_{1}^{\prime}$ and $\sigma_{3}^{\prime}$ are the major and minor principal effective stress, respectively. The Mohr-Coulomb criterion with the intercept at the origin can then be expressed as

$$
\sin \phi^{\prime}=\frac{3 \eta}{6+\eta}=\frac{\sigma_{1}^{\prime}-\sigma_{3}^{\prime}}{\sigma_{1}^{\prime}+\sigma_{3}^{\prime}}
$$

At initial geostatic condition of $\sigma_{2}^{\prime}=\sigma_{3}^{\prime}=K_{0} \sigma_{1}^{\prime}$, equation (5) can be rewritten to calculate the initial friction angle as

$$
\sin \phi_{1}^{\prime}=\frac{1-K_{0}}{1+K_{0}}
$$

where $K_{0}=\left(1-\sin \phi_{\text {crit }}^{\prime}\right)$ follows the Jaky (1944) expression.

The peak friction angle $\phi_{\mathrm{p}}^{\prime}$ was determined according to Bolton (1986) formulas correlating friction angle with relative density and stress level as

$$
\begin{aligned}
& I_{\mathrm{R}}=I_{\mathrm{D}}\left(10-\ln p^{\prime}\right)-1 \\
& \phi_{\mathrm{p}}^{\prime}-\phi_{\text {crit }}^{\prime}=m I_{\mathrm{R}}
\end{aligned}
$$

where $I_{\mathrm{R}}$ is the dilatancy index in the unit of degree, and $m$ is a coefficient equal to 3 for axisymmetric conditions. As noted previously, the mean effective stress $p^{\prime}$ for conical footings in sand is usually $\leq 150 \mathrm{kPa}$, for which Bolton (1987) suggested that equation $(\overline{7})$ is replaced with

$$
I_{\mathrm{R}}=5 I_{\mathrm{D}}-1
$$

The peak dilation angle, $\psi_{\mathrm{p}}$ was also calculated after Bolton (1986) as

$$
\psi_{\mathrm{p}}=\left(\phi_{\mathrm{p}}^{\prime}-\phi_{\text {crit }}^{\prime}\right) / 0.48
$$

The Young's modulus was considered constant along the depth of the sand layer, with $E=25$ and $50 \mathrm{MPa}$ for relative density $I_{\mathrm{D}}=45$ and $90 \%$, respectively. Although stressdependent Young's modulus was adopted in previous numerical simulations performed by Yu et al. (2012), it was reported that the effect on spudcan penetration resistance in sand-over-clay is minimal for the coefficient of stiffness above a certain limit $(5 \mathrm{MPa})$. The Poisson's ratio was taken as $0 \cdot 3$. 


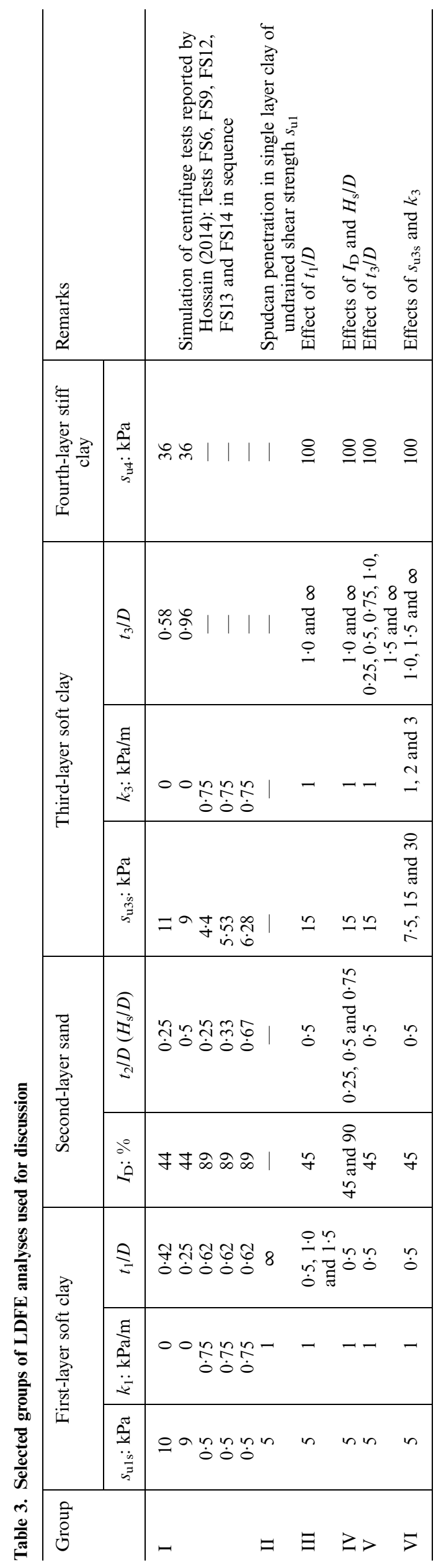

NUMERICAL RESULTS AND DISCUSSION

The penetration resistance profiles from the simulations of the centrifuge tests and part of the parametric study are presented and discussed in this section, with the corresponding parameters assembled in Table 3 . The profiles are presented in terms of total bearing pressure $q_{\mathrm{u}}$ as a function of the normalised penetration depth, $d / D$ or $\left(d-t_{1}\right) / D$.

\section{Simulation of centrifuge tests}

$\mathrm{Hu}$ et al. (2015) used the identical sand model, contact properties and element size and carried out benchmarking analyses against 25 centrifuge tests for spudcan penetration in sand-over-clay deposits. Therefore, in this study, numerical analyses were only performed to validate the numerical model against five centrifuge tests reported by Hossain (2014) for spudcan penetration in a clay-silica sand-clay deposit with ( $D=12 \mathrm{~m}$; tests FS6 and FS9) or without $(D=6 \mathrm{~m}$; tests FS12, FS13 and FS14) a fourth-layer stiff clay. The corresponding soil parameters and layer geometries adopted in the numerical simulations are listed in Group I, Table 3. For tests FS6 and FS9, a medium dense sand layer (FS6: $I_{\mathrm{D}}=44 \%, \quad t_{2} / D=H_{\mathrm{S}} / D=0 \cdot 25, \quad \gamma_{2}^{\prime}=\gamma_{\mathrm{s}}^{\prime}=9.8 \mathrm{kN} / \mathrm{m}^{3}$; FS9: $\left.I_{\mathrm{D}}=44 \%, t_{2} / D=H_{\mathrm{s}} / D=0 \cdot 5, \quad \gamma_{2}^{\prime}=\gamma_{\mathrm{s}}^{\prime}=9 \cdot 8 \mathrm{kN} / \mathrm{m}^{3}\right)$ was sandwiched by two soft clay layers (FS6: $s_{\mathrm{u} 1}=10 \mathrm{kPa}$, $s_{\mathrm{u} 3}=11 \mathrm{kPa}, \quad t_{1} / D=0.42, \quad t_{3} / D=0.58, \quad \gamma_{1}^{\prime}=7 \cdot 1 \mathrm{kN} / \mathrm{m}^{3}, \quad \gamma_{3}^{\prime}=$ $7 \cdot 2 \mathrm{kN} / \mathrm{m}^{3}$; FS9: $s_{\mathrm{u} 1}=s_{\mathrm{u} 3}=9 \mathrm{kPa}, t_{1} / D=0.25, t_{3} / D=0.96$, $\gamma_{1}^{\prime}=7 \cdot 1 \mathrm{kN} / \mathrm{m}^{3}, \gamma_{3}^{\prime}=7 \cdot 2 \mathrm{kN} / \mathrm{m}^{3}$ ), with a bottom layer of stiff clay with $s_{\mathrm{u} 4}=36 \mathrm{kPa}$ and $\gamma_{4}^{\prime}=8 \mathrm{kN} / \mathrm{m}^{3}$. Tests FS12, FS13 and FS14 were carried out for a dense sand layer $\left(I_{\mathrm{D}}=89 \%\right.$, $\left.\gamma_{2}^{\prime}=\gamma_{\mathrm{s}}^{\prime}=11 \mathrm{kN} / \mathrm{m}^{3}\right)$ sandwiched by two non-uniform clay layers $\quad\left(s_{\mathrm{u} 1}=s_{\mathrm{u} 3}=0.5+0.75 z, \quad t_{1} / D=0.62, \quad \gamma_{1}^{\prime}=\gamma_{3}^{\prime}=\right.$ $\left.7 \cdot 1 \mathrm{kN} / \mathrm{m}^{3}\right)$, with $t_{2} / D=H_{\mathrm{s}} / D=0.25, \quad 0.33$ and 0.67 , respectively.

Figures 5(a) and 5(b) show the measured and computed penetration resistance profiles for tests FS6 and FS9, respectively. Note that the analyses for four-layer deposits (e.g. for test FS6) were mostly terminated in layer 3 once the focused aspects of this study, namely, the peak resistance in the second layer and limiting squeezing depth in the third layer, could be clearly measured. For this interbedded medium dense sand layer, reasonable agreement can be seen between the results from the centrifuge model test and numerical analysis in terms of key features of the penetration resistance profile, including the depth and magnitude of the peak resistance in the second layer of sand, the limiting squeezing depth in the third layer of clay and the punchthrough distance. For the peak resistance in the second layer of sand, the numerical results are $\sim 10 \%$ and $0 \%$ lower than the centrifuge test data from tests FS6 and FS9, respectively. In the third layer, the measured limiting squeezing depths are $h_{\mathrm{sq}} / D=0.45$ and 0.71 for tests FS6 and FS9, respectively, compared to the computed values of 0.53 and 0.71 .

For tests FS12, FS13 and FS14, the penetration resistance profiles from the centrifuge model tests and numerical simulations are compared in Fig. 5(c). Overall, for this interbedded dense sand layer, the computed profiles are lower than the measured ones in terms of the peak resistance $(0 \sim 21 \cdot 1 \%)$ and post-peak rate of reduction in the sand layer, and the bearing capacity in the bottom clay layer. The most significant error is associated with the thickest sand layer of $t_{2} / D=H_{\mathrm{s}} / D=0 \cdot 67$. This may be partly due to the underestimation of the strength parameters using the Bolton (1986) equations, compared with the database reported by Andersen $\&$ Schjetne (2013); and partly due to the simplification in the sand model used, that is, the actual stress-strain curve which is concave downward before critical state being simplified as straight lines (Fig. 4), which may underestimate the soil strength. However, it should be noted that the reasonably 


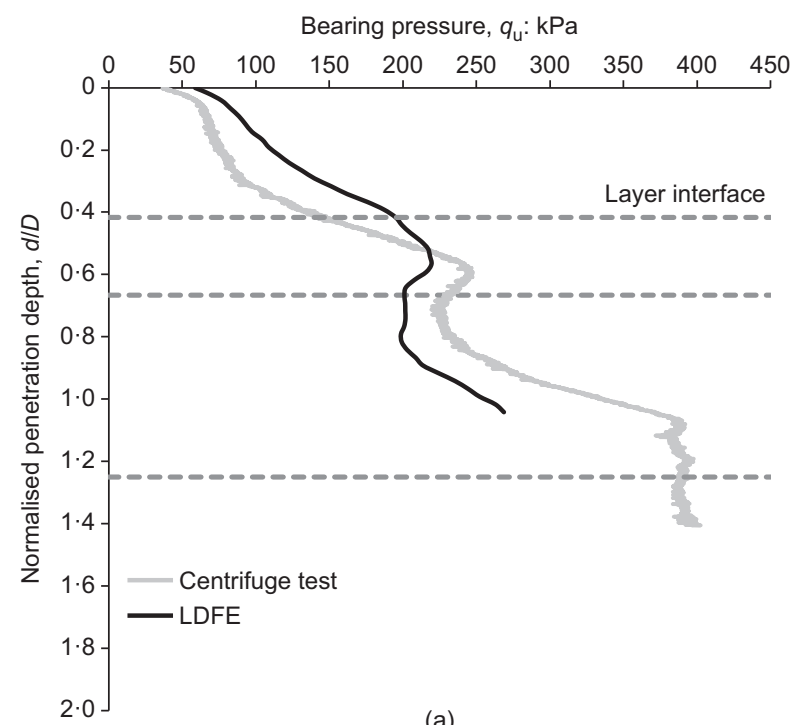

(a)

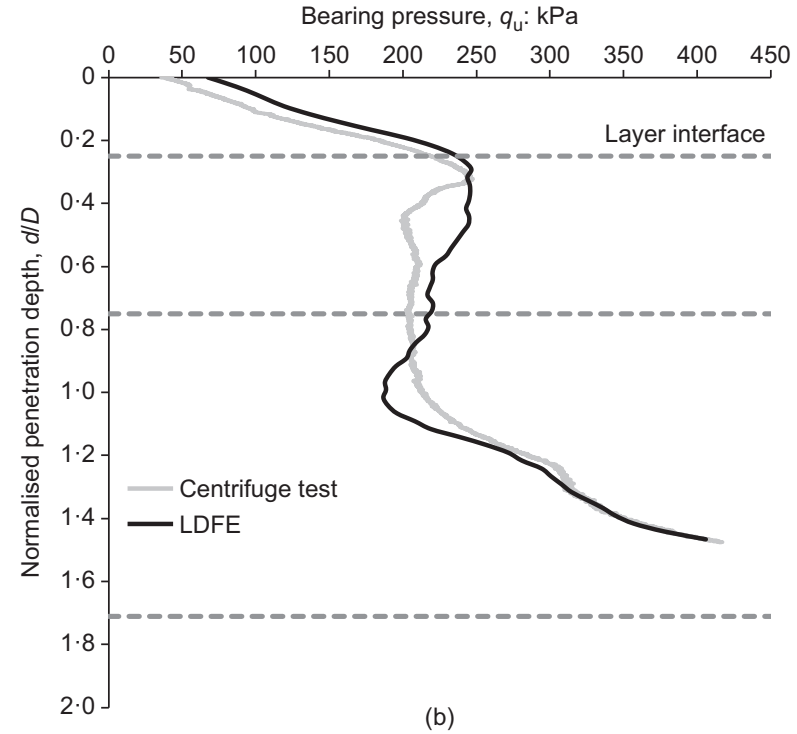

(b)

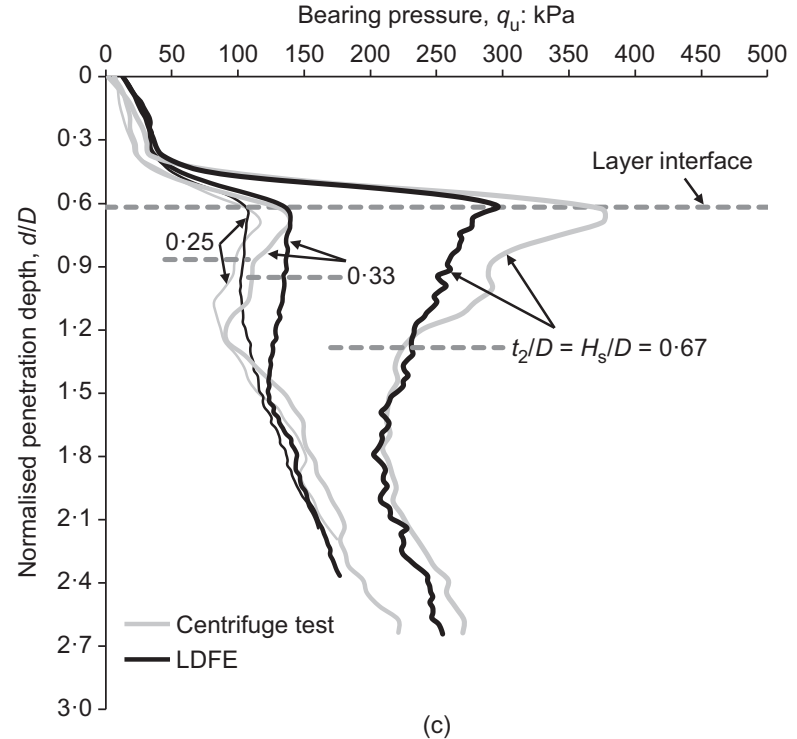

Fig. 5. Comparison of centrifuge test and numerical analysis: (a) test FS6 $\left(D=12 \mathrm{~m}, s_{\mathrm{u} 1}=10 \mathrm{kPa}, s_{\mathrm{u} 3}=11 \mathrm{kPa}, I_{\mathrm{D}}=44 \%, s_{\mathrm{u} 4}=36 \mathrm{kPa}\right.$, $t_{1} I D=0.42, t_{2} I D=H_{\mathrm{s}} I D=0.25, t_{3} / D=0.58 ;$ Group I, Table 3); (b) test FS9 $\left(D=12 \mathrm{~m}, s_{\mathrm{u} 1}=\mathrm{s}_{\mathrm{u} 3}=9 \mathrm{kPa}, I_{\mathrm{D}}=44 \%, s_{\mathrm{u} 4}=36 \mathrm{kPa}\right.$, $t_{1} I D=0 \cdot 25, t_{2} I D=H_{\mathrm{s}} I D=0 \cdot 5, t_{3} I D=0 \cdot 96$; Group I, Table 3); (c) tests FS12, FS13 and FS14 $\left(D=6 \mathrm{~m}, s_{\mathrm{u} 1}=s_{\mathrm{u} 3}=0.5+0 \cdot 75 z, I_{\mathrm{D}}=89 \%\right.$, $t_{1} / D=0 \cdot 62$; Group I, Table 3)

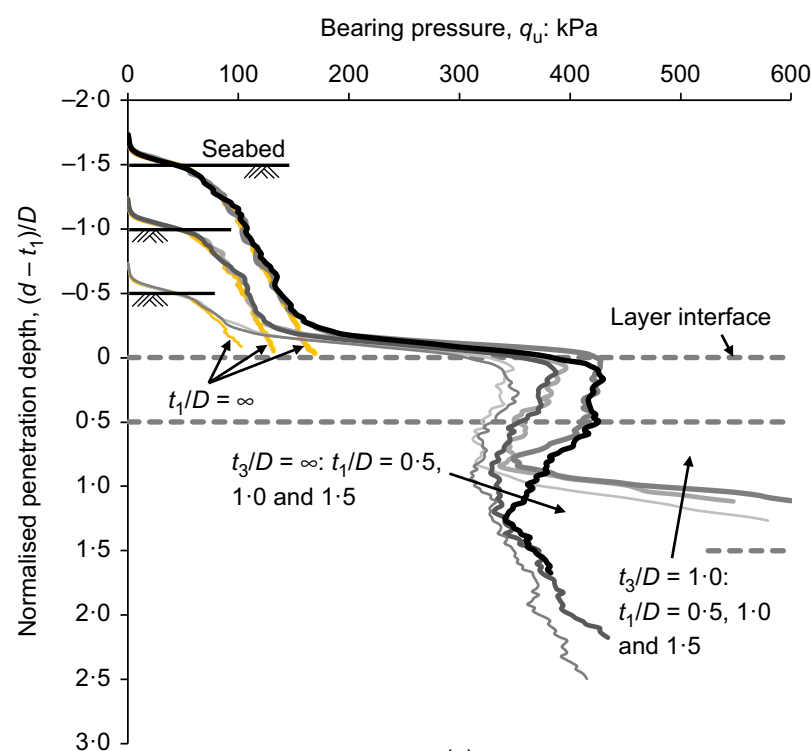

(a)

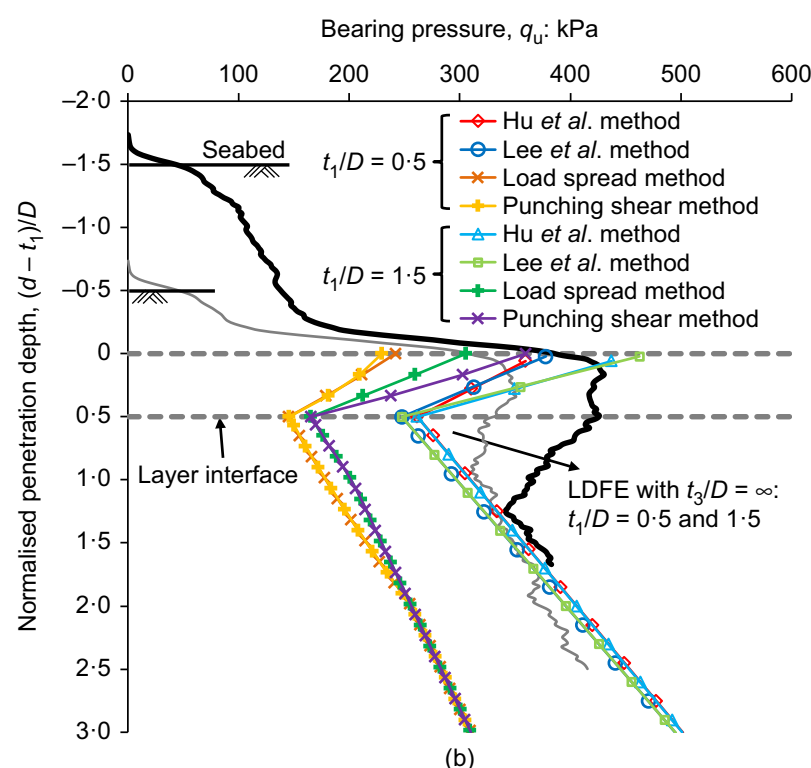

Fig. 6. Effect of first-layer thickness ratio $t_{1} / D$ on penetration resistance $\left(s_{\mathrm{u} 1}=5+1 z \mathrm{kPa}, I_{\mathrm{D}}=45 \%, s_{\mathrm{u} 3}=15+1\left(z-t_{1}-t_{2}\right) \mathrm{kPa}\right.$, $s_{\mathrm{u} 4}=100 \mathrm{kPa}, t_{2} I D=H_{\mathrm{s}} I D=0 \cdot 5$; Group III, Table 3): (a) LDFE analyses; (b) comparison between LDFE analyses and design methods

lower computed capacities, particularly the peak ones in the sand layer, confirm that the potential of punch-through failure will not be underestimated using the extended design methods calibrated against the results from LDFE analyses.

Analyses using the CEL approach for centrifuge tests of spudcan penetration in sand-over-clay deposits have also been performed by Qiu \& Grabe (2012) and Bienen et al. (2015), although a hypoplastic model was employed in their simulations. Similarly to this study, the lower computed peak resistance compared to centrifuge test data has been reported by $\mathrm{Hu}$ et al. (2015), Qiu \& Grabe (2012) and Bienen et al. (2015), with differences of about $4 \sim 27 \%$ (figure 5 of $\mathrm{Hu}$ et al., 2015) and around 9\% (figure 8 of Qiu \& Grabe, 2012; figure 4 of Bienen et al., 2015), respectively.

As for the post-peak penetration resistance, an underestimated post-peak rate of reduction in the sand layer was also reported by $\mathrm{Hu}$ et al. (2015), but reasonable agreement was given between the computed and measured profiles of the increasing penetration resistance in the underlying clay layer. By contrast, an improved simulation of post-peak rate 
of reduction has been given by Qiu \& Grabe (2012) and Bienen et al. (2015) using a hypoplastic model for the sand layer, although the computed penetration resistance in the underlying clay layer has still been either overestimated or underestimated. Nonetheless, for the scope of this study, the post-peak reduction of penetration resistance is not crucial, as only the peak resistance, the stable penetration resistance in the third (clay) layer and the limiting squeezing depth obtained from the penetration resistance profiles were used. These features were reasonably captured by the LDFE analyses conducted.

\section{Effect of first-layer clay}

To explore the effect of the first-layer clay on the penetration resistance, the results of various thickness ratios $t_{1} / D=0.5,1 \cdot 0$ and $1 \cdot 5$, with $\left(t_{3} / D=1 \cdot 0\right)$ and without $\left(t_{3} / D=\infty\right)$ the presence of a fourth (stiff) layer of $s_{\mathrm{u} 4}=$ $100 \mathrm{kPa}$ (Group III, Table 3) are plotted in Fig. 6(a). The undrained shear strengths of the first and third clay layers are $s_{\mathrm{u} 1}=5+1 z \mathrm{kPa}$ and $s_{\mathrm{u} 3}=15+1\left(z-t_{1}-t_{2}\right) \mathrm{kPa}$, respectively, sandwiching a sand layer of $I_{\mathrm{D}}=45 \%$ and $t_{2} / D=H_{\mathrm{s}} / D=0.5$. The penetration resistance profile from the analysis for spudcan penetration in single-layer clay with undrained shear strength $=s_{\mathrm{u} 1}\left(t_{1} / D=\infty\right.$; Group II, Table 3$)$ is also included in the figure to identify the depth of triggering squeezing $d_{\text {sq }}$ (or quantify the limiting squeezing depth $h_{\text {sq }}$ ) in the first layer. Potential for punch-through is indicated by all the profiles in Fig. 6, showing higher $q_{\text {peak }}$ for a thicker first layer (higher $t_{1} / D$ ).

The limiting squeezing depth in the first layer increases slightly with increasing $t_{1} / D$, with a small range of $h_{\mathrm{sq}}=0 \cdot 27 \sim 0 \cdot 33 D$. However, $t_{1} / D$ has minimal effect on the squeezing depth in the third layer (in the presence of the fourth layer). The depth is found, regardless of $t_{1} / D$, as $h_{\mathrm{sq}}=\sim 0.67 D$, which is significantly higher compared to that in the first layer due to the effect of the soil plug trapped at the base of the advancing spudcan.

For clay-sand-clay deposits with $t_{1} / D=0.5$ and 1.5 , the predicted penetration resistance profiles using the design methods listed in Table 1 are included (only for the second and third layers) in Fig. 6(b) for comparison. As can be expected, conservative resistances are provided by the load spread and punching shear methods, which are $67 \cdot 4 \sim 84 \cdot 7 \%$ of the computed values. By contrast, taking the overburden pressure of the overlying clay layer as $q_{0}$ in the Lee et al. and $\mathrm{Hu}$ et al. methods provides approximate estimations for the peak resistance in the sand layer. The penetration resistance profiles predicted using the Lee et al. and $\mathrm{Hu}$ et al. methods also agree reasonably well with the computed profiles in terms of the deep penetration resistance in the third-layer clay in the absence of the fourth layer.

\section{Effect of second-layer sand}

Figure 7(a) compares the penetration resistance profiles for sand layers of relative densities $I_{\mathrm{D}}=45$ and $90 \%$ and thickness ratios $t_{2} / D=H_{\mathrm{s}} / D=0 \cdot 25,0.5$ and 0.75 with the first-layer clay of $s_{\mathrm{u} 1}=5+1 z \mathrm{kPa}$ and $t_{1} / D=0.5$ (Group IV, Table 3). The undrained shear strength of the third layer $s_{\mathrm{u} 3}=15+1\left(z-t_{1}-t_{2}\right) \mathrm{kPa}$ was kept unchanged, with thickness ratios $t_{3} / D=1 \cdot 0$ and $\infty$ and $s_{\mathrm{u} 4}=100 \mathrm{kPa}$. The effects of relative density $I_{\mathrm{D}}$ and sand layer thickness $H_{\mathrm{s}} / D$ on the peak resistance in the sand layer and deep penetration resistance in the underlying clay layer have already been investigated by a number of researchers for two-layer sand-over-clay deposits (Teh et al., 2008, 2010; Lee et al., 2013a, 2013b; Hu et al., 2014a, 2014b). For spudcan penetration in a clay-sand-clay deposit with and without a fourth (stiff) layer, Fig. 7(a) shows

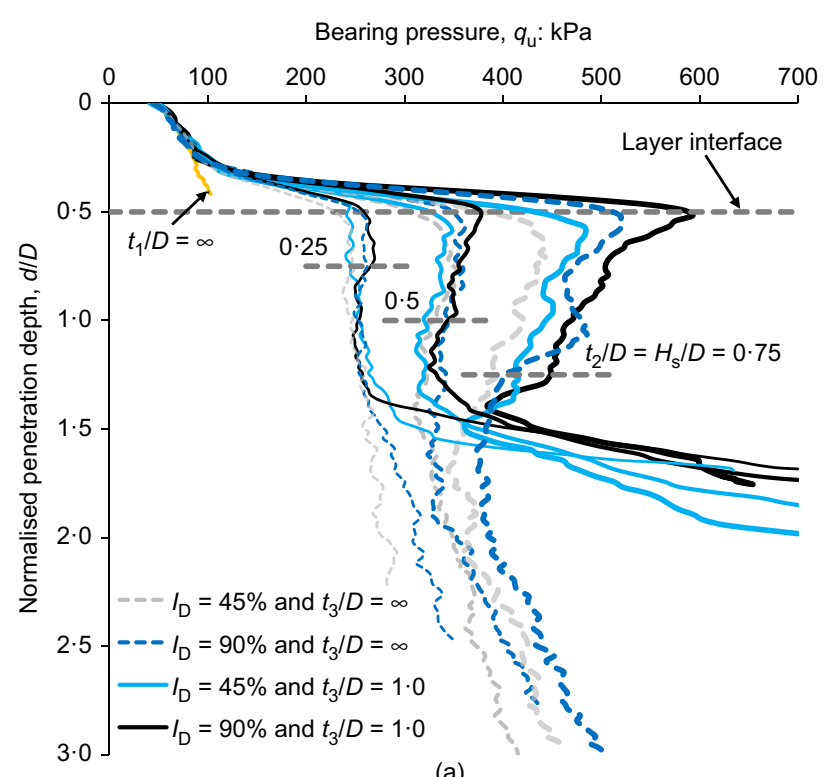

(a)

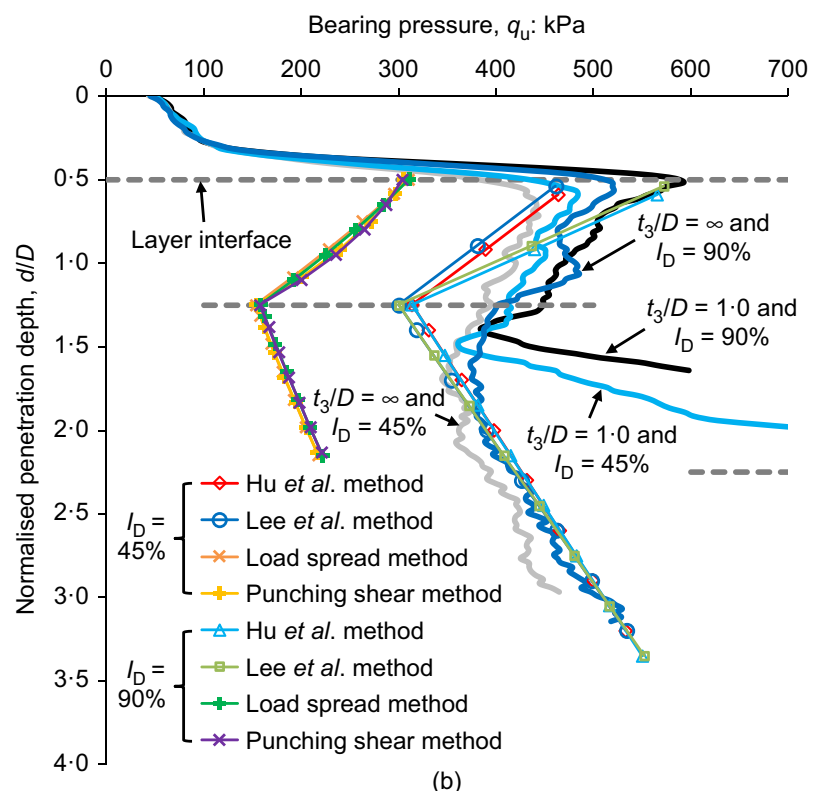

(b)

Fig. 7. Effects of relative density $I_{\mathrm{D}}$ and thickness ratio $H_{\mathrm{s}} / D$ of second-layer sand on penetration resistance $\left(s_{\mathrm{u} 1}=5+1 z \mathrm{kPa}\right.$, $s_{\mathrm{u} 3}=15+1\left(z-t_{1}-t_{2}\right) \mathrm{kPa}, s_{\mathrm{u} 4}=100 \mathrm{kPa}, t_{1} / D=0.5 ;$ Group IV, Table 3): (a) LDFE analyses; (b) comparison of estimated profiles and numerical results for $t_{2} / D=H_{\mathrm{s}} / D=0.75$

similar trends except the effect of the fourth layer on increasing the peak resistance for dense sand (with all $H_{\mathrm{s}} / D$ ) and for medium dense sand (with $H_{\mathrm{s}} / D \geq 0 \cdot 5$ ).

The limiting squeezing depth in the first layer is $h_{\mathrm{sq}}=0 \cdot 27 D$, regardless of $I_{\mathrm{D}}$ and $H_{\mathrm{s}} / D$. With the presence of the fourth-layer stiff clay, $h_{\mathrm{sq}}$ in the third layer increases with increasing $I_{\mathrm{D}}$ and $H_{\mathrm{s}} / D$. For $I_{\mathrm{D}}=45 \%$ and $t_{3} / D=1 \cdot 0, h_{\mathrm{sq}}$ in the third layer increases from $0 \cdot 3 D$ to $0 \cdot 76 D$ as $H_{\mathrm{s}} / D$ increases from 0.25 to 0.75 ; while for a consistent value of $H_{\mathrm{s}} / D=0 \cdot 75$, the values of $h_{\mathrm{sq}}$ in the third layer are $0 \cdot 76 D$ and $0 \cdot 86 D$, respectively, for $I_{\mathrm{D}}=45$ and $90 \%$.

To compare the performance of the design methods in Table 1, the predicted penetration resistance profiles for $t_{2} / D=H_{\mathrm{s}} / D=0.75, \quad I_{\mathrm{D}}=45$ and $90 \%$ and $t_{3} / D=\infty$ are plotted in Fig. 7(b), together with the corresponding numerical results. For $t_{3} / D=1 \cdot 0$, the predictions from ISO methods are identical with those for $t_{3} / D=\infty$ before squeezing comes into effect (e.g. see Fig. 8). In the absence of the 


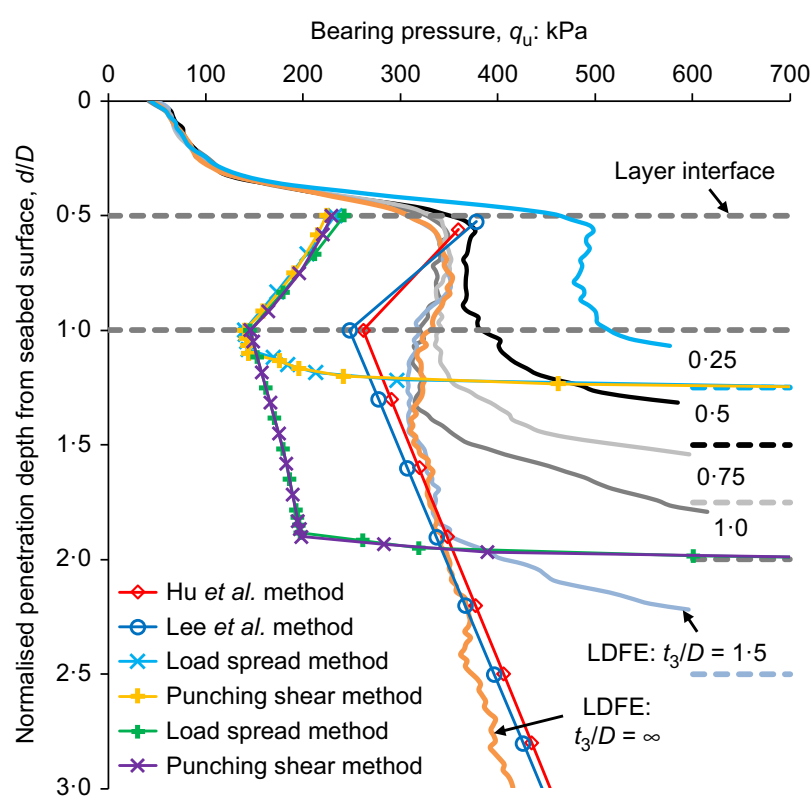

Fig. 8. Effect of third-layer thickness ratio $t_{3} / D$ on penetration resistance $\left(s_{\mathrm{u} 1}=5+1 z \mathrm{kPa}, I_{\mathrm{D}}=45 \%, s_{\mathrm{u} 3}=15+1\left(z-t_{1}-t_{2}\right) \mathrm{kPa}\right.$, $s_{\mathrm{u} 4}=100 \mathrm{kPa}, t_{1} / D=t_{2} / D=H_{\mathrm{s}} / D=0 \cdot 5$; Group V, Table 3)

fourth layer, the peak resistance, along with the effect of $I_{\mathrm{D}}$, is well predicted by the Lee et al. and $\mathrm{Hu}$ et al. methods. By comparison, the ISO methods predict $29 \cdot 3 \sim 41 \cdot 7 \%$ lower peak resistance than the computed values. However, the influence of the fourth layer on the peak resistance cannot be captured by any of these methods.

\section{Effect of third-layer clay}

Thickness ratio $\mathrm{t}_{3} / \mathrm{D}$. The penetration resistance profiles obtained from numerical analyses of Group V in Table 3 are plotted in Fig. 8 to investigate the effect of the third-layer thickness ratio $t_{3} / D$. The value of $t_{3} / D$ was varied from $0 \cdot 25$ to $\infty$. The other parameters were kept constant, including strength parameters $\left(s_{\mathrm{u} 1}=5+1 z \mathrm{kPa}, I_{\mathrm{D}}=45 \%, s_{\mathrm{u} 3}=15+1\right.$ $\left.\left(z-t_{1}-t_{2}\right) \quad \mathrm{kPa}, \quad s_{\mathrm{u} 4}=100 \mathrm{kPa}\right)$ and thickness ratios $\left(t_{1} / D=t_{2} / D=H_{\mathrm{s}} / D=0 \cdot 5\right)$.

For $t_{2} / D=H_{\mathrm{s}} / D=0.5$ and $t_{3} / D \geq 0.75$, the effect of the presence of the fourth (stiff) layer on the peak resistance in the sand layer is trivial. The effect is becoming profound as the third layer is becoming thinner (e.g. $t_{3} / D \leq 0 \cdot 5$ ), with $q_{\text {peak }}$ being 6.7 and $41 \cdot 1 \%$ higher for $t_{3} / D=0.5$ and $0 \cdot 25$, respectively, compared with that for $t_{3} / D \geq 0 \cdot 75$.

To explore the critical value of $t_{3} / D$ for this influence, the values of $q_{\text {peak }}$ obtained from analyses with a fourth (stiff) layer are normalised by the corresponding value from analysis for $t_{3} / D=\infty$, leading to a factor, $\lambda$. The values of $\lambda$ for different combinations of $H_{\mathrm{s}} / D$ and $I_{\mathrm{D}}$ are plotted in Fig. 9 as a function of $t_{3} / H_{\mathrm{s}}$, which is best fitted by

$$
\lambda=1+1 \cdot 4 \mathrm{e}^{-2 \cdot 2 t_{3} / H_{\mathrm{s}}}
$$

Equation (11) indicates that the peak resistance $q_{\text {peak }}$ increases by more than $10 \%$ for $t_{3} / H_{\mathrm{s}}<1 \cdot 2$.

The penetration resistance profiles predicted for $t_{3} / D=\infty$ using Lee et al. and $\mathrm{Hu}$ et al. methods are included in Fig. 8. For ISO methods, the bottom-up approach is used and the predicted profiles for $t_{3} / D=0.25$ and 1.0 are included for comparison. It can be seen that for $t_{3} / D \geq 0 \cdot 5$, the estimated peak resistances from the Lee et al. and $\mathrm{Hu}$ et al. methods are reasonable. The errors between the computed and estimated peak resistances increase to $24 \cdot 2 \%$ (Lee et al. method) and $27 \cdot 9 \%$ (Hu et al. method) for $t_{3} / D=0 \cdot 25$.

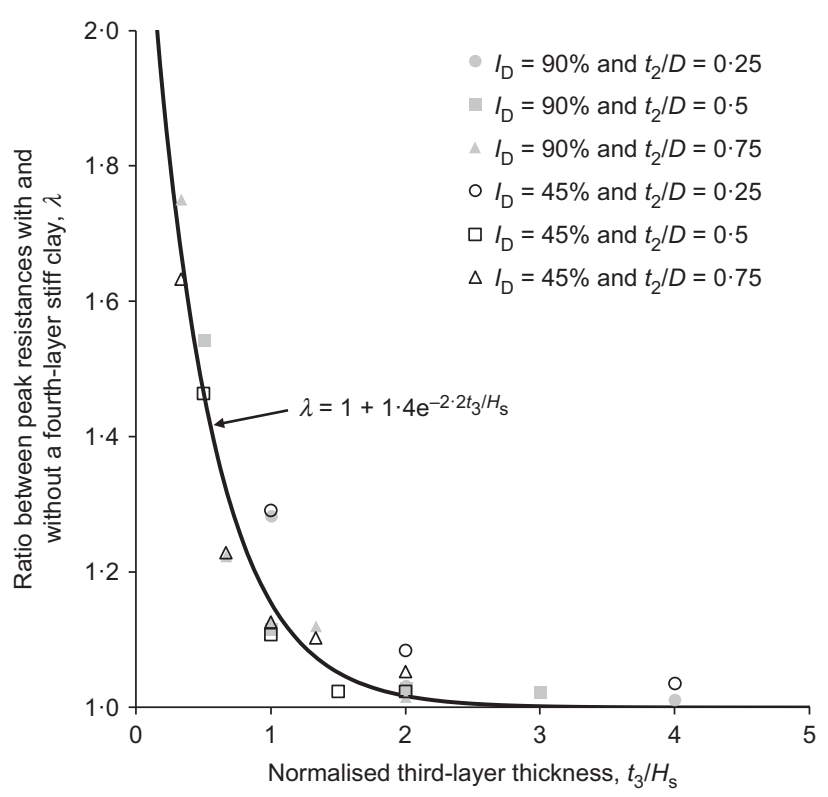

Fig. 9. Effect of $t_{3} / D$ on increasing the peak resistance in sand layer

Again, ISO methods provide a conservative estimate for full resistance profiles in the second and third layers, with the peak resistance being $29 \cdot 2 \sim 55 \cdot 1 \%$ lower compared to the numerical results. Note that the estimated profiles from the ISO methods are very similar before squeezing. This is because the estimated limiting squeezing depth $h_{\mathrm{sq}}$ in the third-layer clay is always lower than the lowest thickness ratio $t_{3} / D=0 \cdot 25$ considered in this study, resulting in no update of the undrained shear strength in the calculation of the secondthird sand-clay layering system.

Strength parameters $\mathrm{s}_{u 3 s}$ and $\mathrm{k}_{3}$. To explore the effect of the third-layer undrained shear strength, two series of numerical analyses were performed for $(a) s_{\mathrm{u} 3 \mathrm{~s}}=7 \cdot 5,15$ and $30 \mathrm{kPa}$ with $k_{3}=1 \mathrm{kPa} / \mathrm{m}$; and $(b) k_{3}=1,2$ and $3 \mathrm{kPa} / \mathrm{m}$, with $s_{\mathrm{u} 3 \mathrm{~s}}=15 \mathrm{kPa}$. The third-layer thickness ratio was varied as $t_{3} / D=1.0,1.5$ and $\infty$, with the other parameters kept constant as $s_{\mathrm{u} 1}=5+1 z \mathrm{kPa}, I_{\mathrm{D}}=45 \%, s_{\mathrm{u} 4}=100 \mathrm{kPa}$ and $t_{1} / D=t_{2} / D=H_{\mathrm{s}} / D=0 \cdot 5$ (Group VI, Table 3). Fig. 10 shows the computed penetration resistance profiles (note that the results are only plotted for $k_{3}=1$ and $3 \mathrm{kPa} / \mathrm{m}$ in Fig. 10(b) for clarity). The penetration resistance increases with increasing $s_{\mathrm{u} 3 \mathrm{~s}}$ or $k_{3}$, with the effect of the former more profound. These are related to the increase of strength ratio between clay and sand, and hence the increase of end bearing capacity and frictional resistance of the sand plug.

For spudcan penetration in the third layer, the limiting squeezing depths are $h_{\mathrm{sq}}=0.67 \sim 0.74 D$ for $t_{3} / D=1.0$ and $h_{\mathrm{sq}}=0.5 \sim 0.61 D$ for $t_{3} / D=1.5$, with lower values in the ranges resulted from higher value of $s_{\mathrm{u} 3 \mathrm{~s}}$ or $k_{3}$. This is caused by the soil plug carried down by the advancing spudcan from the first and second layers, which somewhat diminishes with penetration depth and at a slightly higher rate for a stronger clay layer (i.e. higher strength parameters $s_{\mathrm{u} 3 \mathrm{~s}}$ and $k_{3}$ ).

\section{SUGGESTED IMPROVEMENTS OF EXISTING DESIGN METHODS}

Peak resistance in sand layer

As discussed previously, for clay-sand-clay deposits, the peak resistance in the second-layer sand can be estimated by the $\mathrm{Hu}$ et al. or Lee et al. method with reasonable accuracy, 


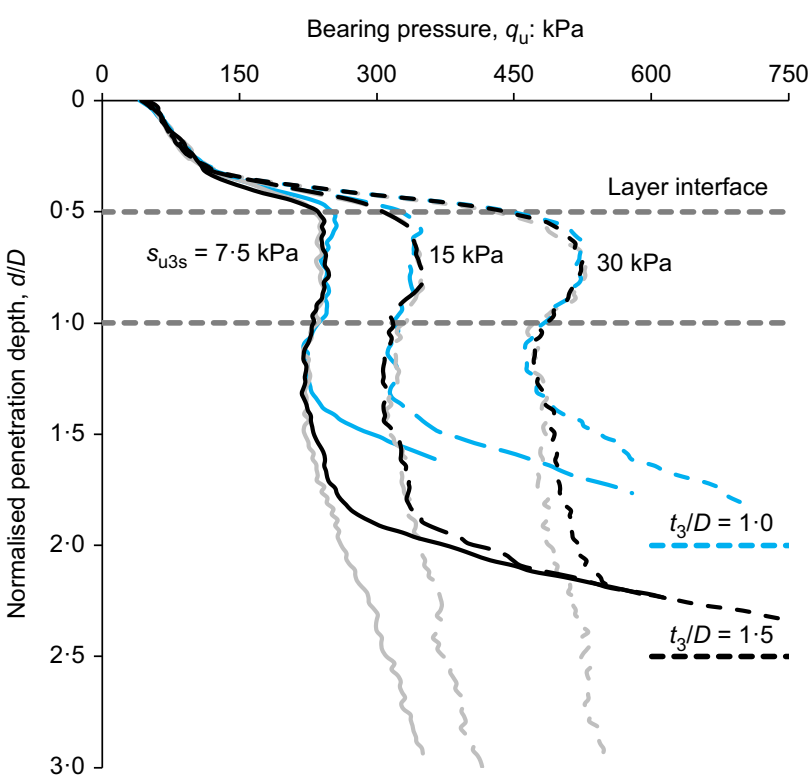

(a)

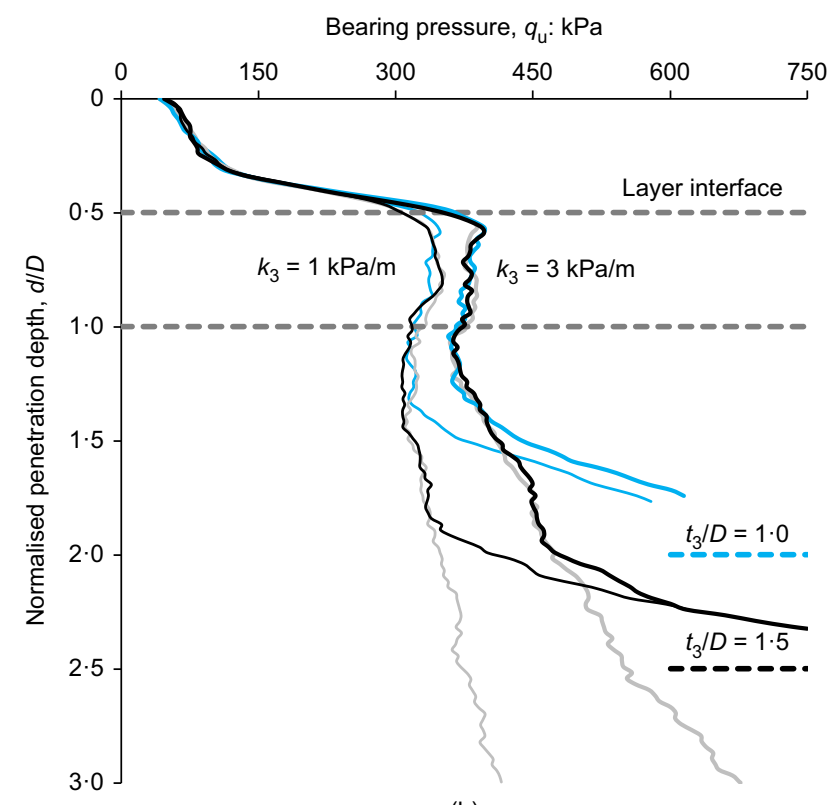

(b)

Fig. 10. Effect of third-layer strength parameters $s_{\mathrm{u} 3 \mathrm{~s}}$ and $\boldsymbol{k}_{3}$ on penetration resistance $\left(s_{\mathrm{u} 1}=5+1 z \mathrm{kPa}, \quad I_{\mathrm{D}}=45 \%, \quad s_{\mathrm{u} 3}=15+1\right.$ $\left(z-t_{1}-t_{2}\right) \mathrm{kPa}, s_{\mathrm{u} 4}=100 \mathrm{kPa}, t_{1} I D=t_{2} I D=H_{\mathrm{s}} I D=0.5$; Group VI, Table 3): (a) effect of $s_{\mathrm{u} 3 \mathrm{~s}}$; (b) effect of $k_{3}$

whereas it is underestimated by the ISO methods. However, in the presence of a strong fourth layer with a small value of $t_{3} / H_{\mathrm{s}}$, all design methods may provide an overly conservative estimation. This can be improved in two ways: (a) multiply the estimated $q_{\text {peak }}$ from the Lee et al. or $\mathrm{Hu}$ et al. method by $\lambda$ (equation (11)); or (b) use an equivalent undrained shear strength $s_{\text {ues }}$ at the sand-clay layer interface (i.e. replacing $s_{\mathrm{u} 3 \mathrm{~s}}$ with $s_{\mathrm{ues}}$ ) that incorporates the influence of the fourth (strong) layer in the design formulas of a sand-over-clay layering system. Design formulas for $s_{\text {ues }}$ are developed in this section.

The results from numerical analyses with $t_{3} / H_{\mathrm{s}} \leq 2 \cdot 0$ and centrifuge tests (FS6 and FS9) were used to calibrate the values of $s_{\text {ues }}$ for each design method. $s_{\text {ues }}$ was selected so that the predicted peak resistance from the design method matched with the computed or measured value. The normalised values of $s_{\mathrm{ues}} / s_{\mathrm{u} 3 \mathrm{~s}}$ are plotted in Fig. 11. For ISO methods
(Fig. 11(a)), design formulas are derived from curve fitting to provide a relatively conservative estimation of $s_{\text {ues }}$ and expressed as

$$
\frac{s_{\mathrm{ues}}}{s_{\mathrm{u} 3 \mathrm{~s}}}=1 \cdot 3+0 \cdot 6 I_{\mathrm{D}}\left(\frac{t_{3}}{H_{\mathrm{s}}}\right)^{-1}\left(1+\frac{k_{3} D}{s_{\mathrm{u} 3 \mathrm{~s}}}\right)
$$

for load spread method

$$
\frac{s_{\mathrm{ues}}}{s_{\mathrm{u} 3 \mathrm{~s}}}=1 \cdot 4+0 \cdot 8 I_{\mathrm{D}}\left(\frac{t_{3}}{H_{\mathrm{s}}}\right)^{-1}\left(1+\frac{k_{3} \mathrm{D}}{s_{\mathrm{u} 3 \mathrm{~s}}}\right)
$$

for punching shear method

The relative density $I_{\mathrm{D}}$ is expressed as a decimal. For $t_{3} / H_{\mathrm{s}}>2 \cdot 0, s_{\text {ues }} / s_{\mathrm{u} 3 \mathrm{~s}}=1.3$ and 1.4 can be adopted for the load spread and punching shear methods, respectively.

For Lee et al. and $\mathrm{Hu}$ et al. methods (Fig. 11(b)), a consistent design formula can be used and expressed as

$$
\begin{aligned}
\frac{s_{\mathrm{ues}}}{s_{\mathrm{u} 3 \mathrm{~s}}} & =0.8+0 \cdot 1\left[\left(\frac{H_{\mathrm{s}}+t_{3}}{D}\right)^{-0.5}\left(\frac{t_{3}}{H_{\mathrm{s}}}\right)^{-1}\left(1+\frac{k_{3} D}{s_{\mathrm{u} 3 \mathrm{~s}}}\right)\right]^{1 \cdot 7} \\
& \geq 1.0
\end{aligned}
$$

A lower bound of 1.0 is set for equation (14), indicating that the third-layer clay is thick enough to avoid the effect of the strong fourth layer.

Equations (12)-(14) are proposed only to quantify the favourable effect of the presence of a strong fourth layer on the peak resistance (i.e. increasing the peak resistance) in the sand (second) layer, based on the results from analyses in which there is a considerably stronger (stiff clay) fourth layer compared to the third layer. Therefore, it is suggested that the equations may also be applicable to sites where there is a fourth layer of sand, but not to the deposits where the fourth layer is weaker compared to the third layer, which may lead to a lower peak resistance in the second layer followed by a continual decreasing resistance profile in the third and fourth layers, as reported by Hossain (2014).

\section{Limiting squeezing depth}

For spudcan penetration in the third-layer clay confronting a fourth (strong) layer, $h_{\mathrm{sq}}$ increases significantly due to the soil plug trapped by the advancing spudcan. As the sand is much stronger than the clay, the base of the soil plug acts like a footing base and forces the third-layer soft clay to squeeze out. Therefore, it is assumed that the squeezing response is triggered once the distance from the base of the soil plug to the third-fourth layer interface is within the conventional limiting squeezing depth for spudcan penetration in clays (a range of $h_{\mathrm{sq}}=0.17 \sim 0.2 D$ observed in the centrifuge tests reported by Hossain et al. (2011) and Hossain (2014)). As such, for a total plug thickness $H_{\text {plug }}$ trapped beneath the advancing spudcan, $h_{\mathrm{sq}} / D=\operatorname{Max}\left(H_{\mathrm{plug}} / D+0 \cdot 18,0 \cdot 25\right)$ is adopted in the third layer, with a lower bound of $h_{\mathrm{sq}} / D=0.25$ observed from the numerical analyses and assuming a consistent limiting squeezing depth of $0 \cdot 18 D$ between clays. The depth $d_{\mathrm{sq}} / D$ is thus calculated as

$$
\begin{aligned}
\frac{d_{\mathrm{sq}}}{D}= & \frac{\left(t_{1}+t_{2}+t_{3}\right)}{D}-\frac{h_{\mathrm{sq}}}{D}=\frac{\left(t_{1}+t_{2}+t_{3}\right)}{D} \\
& -\operatorname{Max}\left[\left(\frac{H_{\mathrm{plug}}}{D}+0 \cdot 18\right), 0 \cdot 25\right]
\end{aligned}
$$

Once $H_{\text {plug }}$ at $d=d_{\text {sq }}$ is known, the limiting squeezing depth $h_{\mathrm{sq}}$ can then be determined. As such, a design formula is 


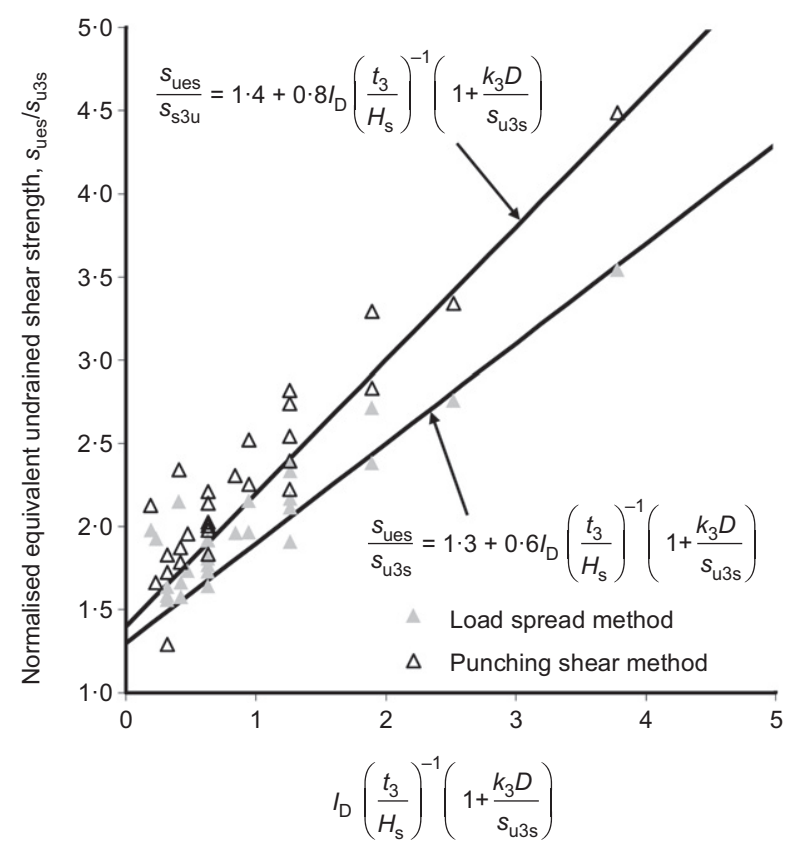

(a)

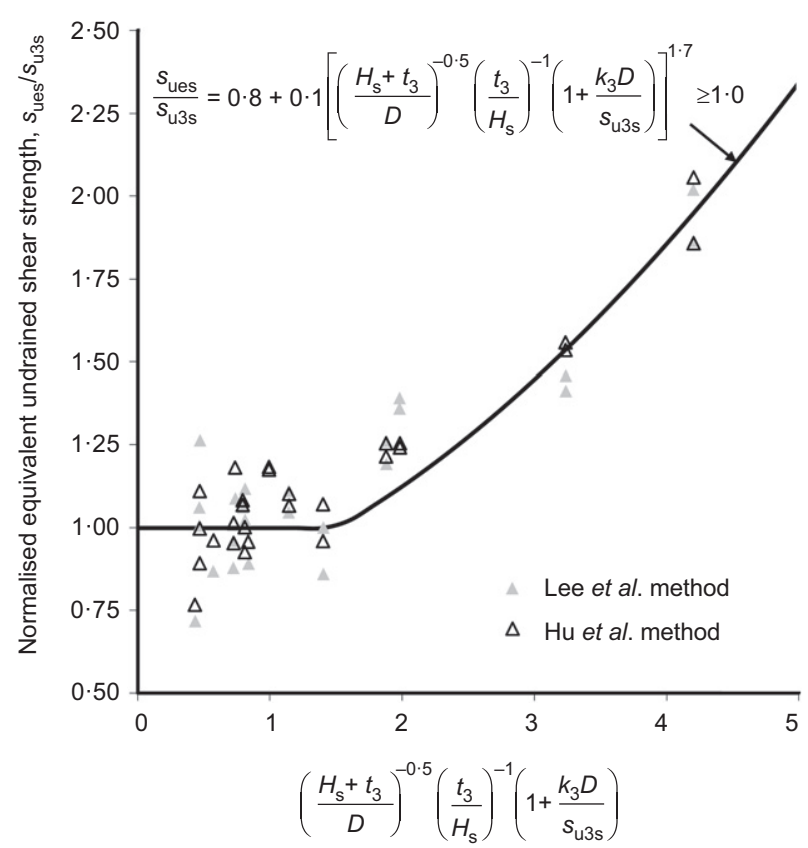

(b)

Fig. 11. Design charts for equivalent undrained shear strength $s_{\text {ues }}$ at sand-clay layer interface: (a) ISO methods; (b) Lee et al. and Hu et al. methods

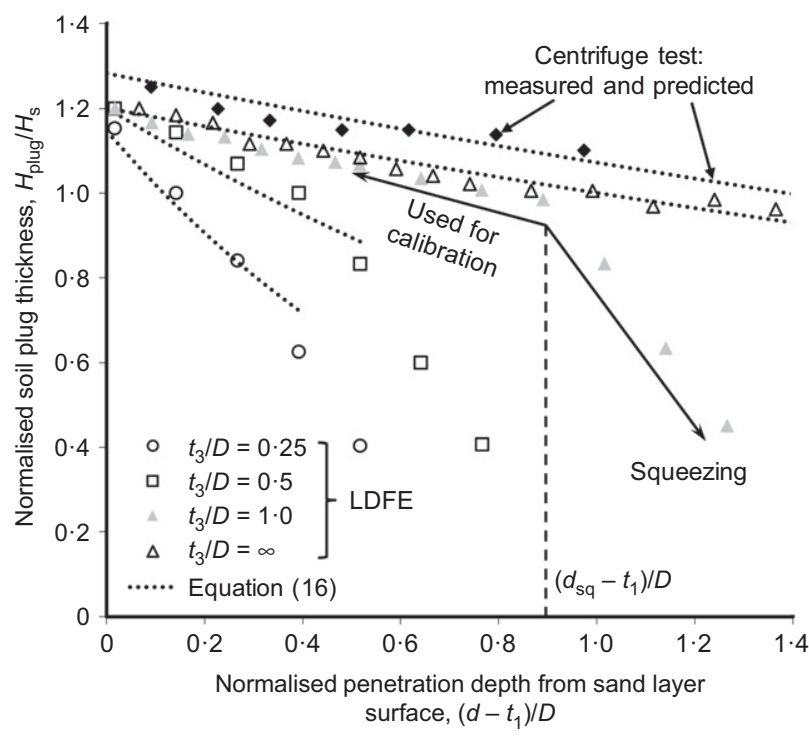

Fig. 12. Evolution of soil plug thickness (LDFE: $s_{\mathrm{u} 1}=5+1 z \mathrm{kPa}$, $I_{\mathrm{D}}=90 \%, \quad s_{\mathrm{u} 3}=15+1\left(z-t_{1}-t_{2}\right) \quad \mathrm{kPa}, \quad t_{1} / D=t_{2} / D=H_{\mathrm{s}} / D=0 \cdot 5$, $s_{\mathrm{u} 4}=100 \mathrm{kPa}$; centrifuge test FS9: $s_{\mathrm{u} 1}=9 \mathrm{kPa}, \quad I_{\mathrm{D}}=44 \%$, $\left.s_{\mathrm{u} 3}=9 \mathrm{kPa}, t_{1} I D=0 \cdot 25, t_{2} l D=H_{\mathrm{s}} / D=0 \cdot 5, t_{3} l D=0 \cdot 96, s_{\mathrm{u} 4}=36 \mathrm{kPa}\right)$

proposed to estimate the evolution of soil plug thickness as a function of spudcan penetration depth based on the variation of soil plug measured in the performed numerical analyses, and expressed as

$$
H_{\text {plug }} / H_{\mathrm{s}}=f_{1} \mathrm{e}^{-f_{2}\left(d-t_{1}\right) / D}
$$

Examples of the evolution of soil plug thickness from LDFE analyses are plotted in Fig. 12 for $s_{\mathrm{u} 1}=5+1 z \mathrm{kPa}, I_{\mathrm{D}}=90 \%$, $s_{\mathrm{u} 3}=15+1\left(z-t_{1}-t_{2}\right) \mathrm{kPa}$ and $t_{1} / D=t_{2} / D=H_{\mathrm{s}} / D=0.5$ with $t_{3} / D=0 \cdot 25,0 \cdot 5,1 \cdot 0$ and $\infty$ and $s_{\mathrm{u} 4}=100 \mathrm{kPa}$. For analyses with a fourth (strong) layer, only the soil plug thickness before the depth of triggering squeezing was used. The soil plug thickness $H_{\text {plug }} / H_{\mathrm{s}}$ at different penetration depths, obtained from each numerical analysis, was used to calibrate the coefficients $f_{1}$ and $f_{2}$, with $f_{1}$ expressed as

$$
f_{1}=0 \cdot 8+0 \cdot 2\left(\frac{H_{\mathrm{s}}}{D}\right)^{-1} \operatorname{Min}\left[\left(\frac{H_{\mathrm{s}}+t_{3}}{D}\right)^{0.5}, 1 \cdot 0\right] \geq 1 \cdot 0
$$

Figure 12 shows that the soil plug thickness decays at a higher rate for lower $t_{3} / D$. According to all the numerical data, it is found that this effect is prominent for $t_{3} / D<1.0$ and $t_{3} / H_{\mathrm{s}} \leq 1 \cdot 5$. As such, $f_{2}$ is expressed as

$$
\begin{aligned}
& f_{2}=0.18+1.4\left[I_{\mathrm{D}}^{-0.5}\left(\frac{H_{\mathrm{s}}}{D}\right)^{-2}\left(\frac{s_{\mathrm{u} 3 \mathrm{~s}}}{\gamma_{3}^{\prime} D}\right)\left(\frac{k_{3}}{\gamma_{\mathrm{s}}^{\prime}}\right)\right]^{3} \\
& \text { for } t_{3} / D \geq 1.0 \text { or } t_{3} / H_{\mathrm{s}}>1.5 \\
& f_{2}=1.2\left[I_{\mathrm{D}}^{-0.5}\left(\frac{t_{3}^{2}}{D H_{\mathrm{s}}}\right)^{-1}\left(\frac{H_{\mathrm{s}}}{D}\right)^{-2}\left(\frac{s_{\mathrm{u} 3 \mathrm{~s}}}{\gamma_{3}^{\prime} D}\right)\left(\frac{k_{3}}{\gamma_{\mathrm{s}}^{\prime}}\right)\right]^{0.5} \\
& \text { for } t_{3} / D<1.0 \text { and } t_{3} / H_{\mathrm{s}} \leq 1.5
\end{aligned}
$$

The relationship between equations (17)-(19) and the corresponding numerical data is plotted in Fig. 13. Using the estimated coefficients, the estimated evolution of $H_{\text {plug }} / H_{\mathrm{s}}$ from equation (16) is also plotted in Fig. 12, showing reasonable agreement with the numerical data before the depth of squeezing. In addition, the variation of soil plug thickness for centrifuge test FS9 is used to validate equations (16)-(19), with the measured data and predicted profile compared in Fig. 12. The comparison embodies reasonable accuracy of the proposed formulas.

As $d_{\text {sq }}$ and $H_{\text {plug }}$ are both a function of penetration depth, an iterative approach is required between equations (15) and (16) to calculate the value of $d_{\mathrm{sq}}$ ( or $\left.h_{\mathrm{sq}}\right)$. 


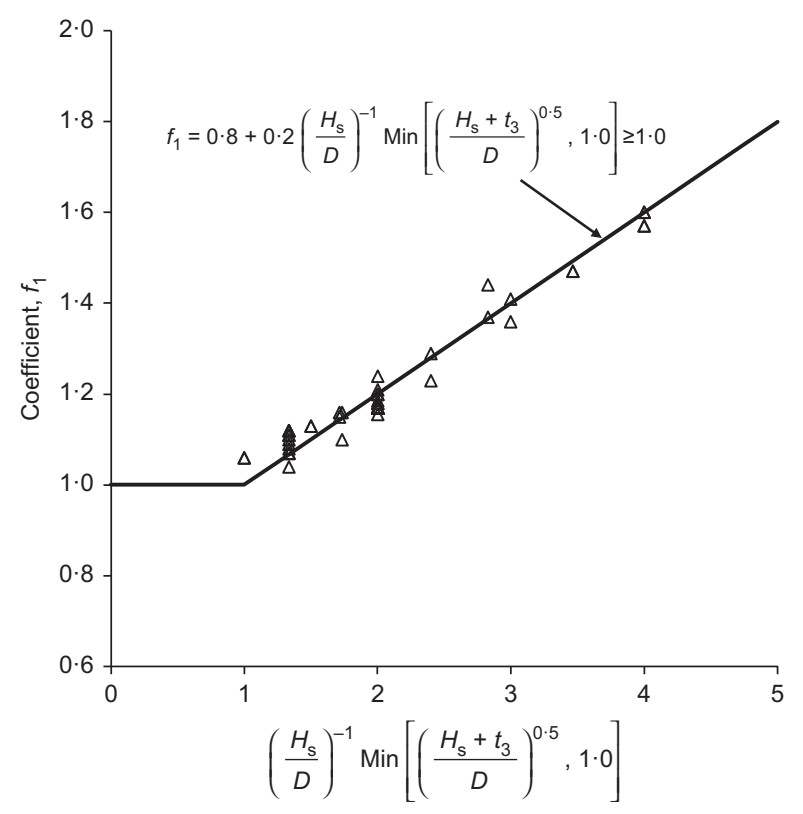

(a)

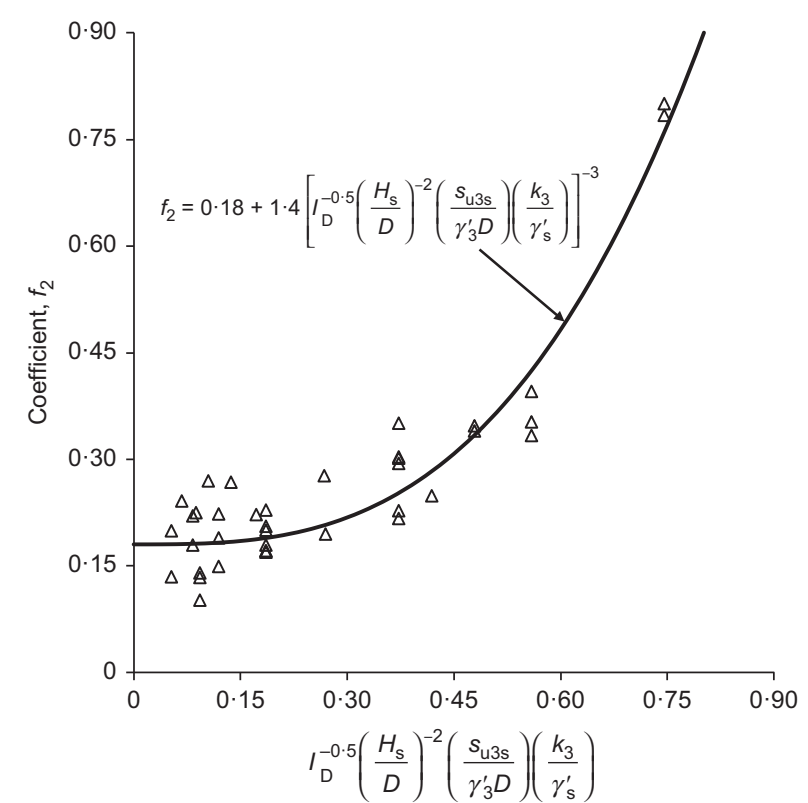

(b)

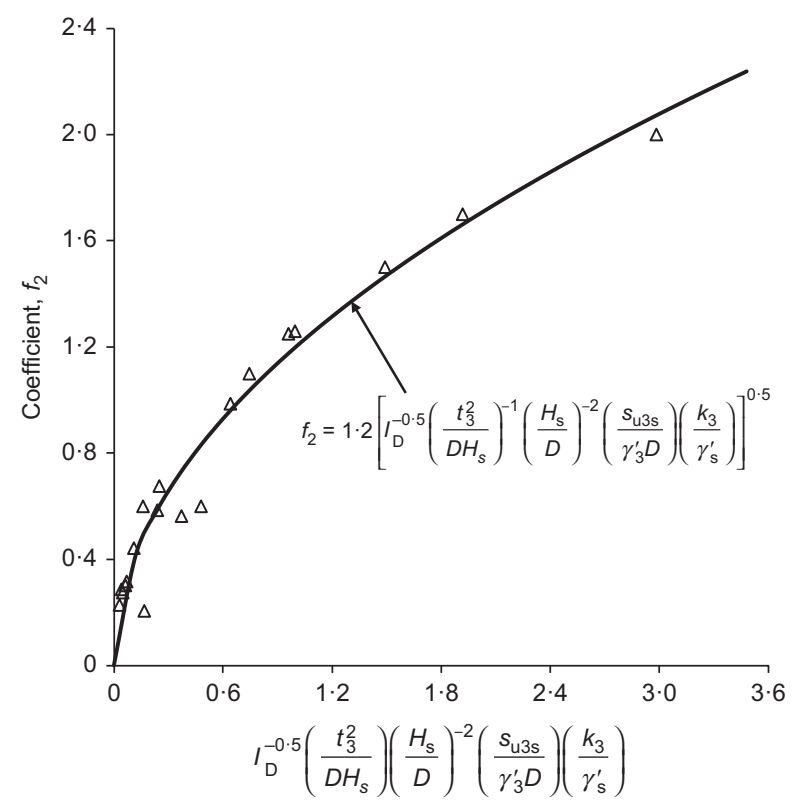

(c)

Fig. 13. Design charts for coefficients $f_{1}$ and $f_{2}$ : (a) design chart for $f_{1}$; (b) design chart for $f_{2}$ for $t_{3} / D \geq 1 \cdot 0$ or $t_{3} / H_{\mathrm{s}}>1 \cdot 5$; (c) design chart for $f_{2}$ for $t_{3} / D<1 \cdot 0$ and $t_{3} / H_{\mathrm{s}} \leq 1 \cdot 5$

\section{OVERALL PERFORMANCE OF IMPROVED \\ DESIGN METHODS}

Peak resistance in sand layer

The normalised peak resistance depths, $\left(d_{\mathrm{p}}-t_{1}\right) / H_{\mathrm{s}}$, measured from the centrifuge tests and computed from the numerical analyses are plotted in Fig. 14 as a function of the corresponding measured ( $\left.q_{\text {peak,meas }}\right)$ or computed $\left(q_{\text {peak,comp }}\right)$ peak resistance. For a spudcan penetrating with a trapped soft clay layer (from the surface layer), $\left(d_{\mathrm{p}}-t_{1}\right) / H_{\mathrm{s}}$ ranges from 0.017 to $0 \cdot 233$, with the average value of $0 \cdot 132$ lying close to $0 \cdot 12$ suggested by Teh et al. (2010) and $\mathrm{Hu}$ et al. (2014a) for a clean spudcan (without trapped soils from upper layers).

The design methods listed in Table 1 with and without employing $s_{\text {ues }}$ and $\lambda$ are used to estimate the peak resistance for the numerical analyses and centrifuge tests. Fig. 15 shows the ratios of the estimated ( $\left.q_{\text {peak,est }}\right)$ to measured or computed peak resistances, as a function of the corresponding measured or computed values. The Lee et al. method is only applicable for $H_{\mathrm{s}} / D<0.9$ (see Table 1) and hence it was not used to predict the cases with $H_{\mathrm{s}} / D \geq 0 \cdot 9$. The statistics for the performance of different methods are compared in Table 4.

Without employing $s_{\text {ues }}$ and $\lambda$, the Lee et al. and Hu et al. methods provide reasonable estimations for most cases (i.e. $\quad 0.85 \leq q_{\text {peak,est }} / q_{\text {peak,meas }}$ or $q_{\text {peak,est }} / q_{\text {peak,comp }} \leq 1.15$ ) except those with a thin third layer, whereas the ISO methods provide conservative peak resistances for all cases presented. This is mainly because $(a)$ in the ISO methods, lower (i.e. using $K_{\mathrm{s}}$ in the punching shear method) or no contribution (in the load spread method) from frictional resistance around the sand plug periphery is considered; and $(b)$ in the punching shear method, the projected bearing area of the underlying clay layer $(=A)$ is smaller than that observed in centrifuge tests.

The estimations are improved by using the equivalent shear strength $s_{\text {ues }}$ (equations (12)-(14)) or multiplying the 


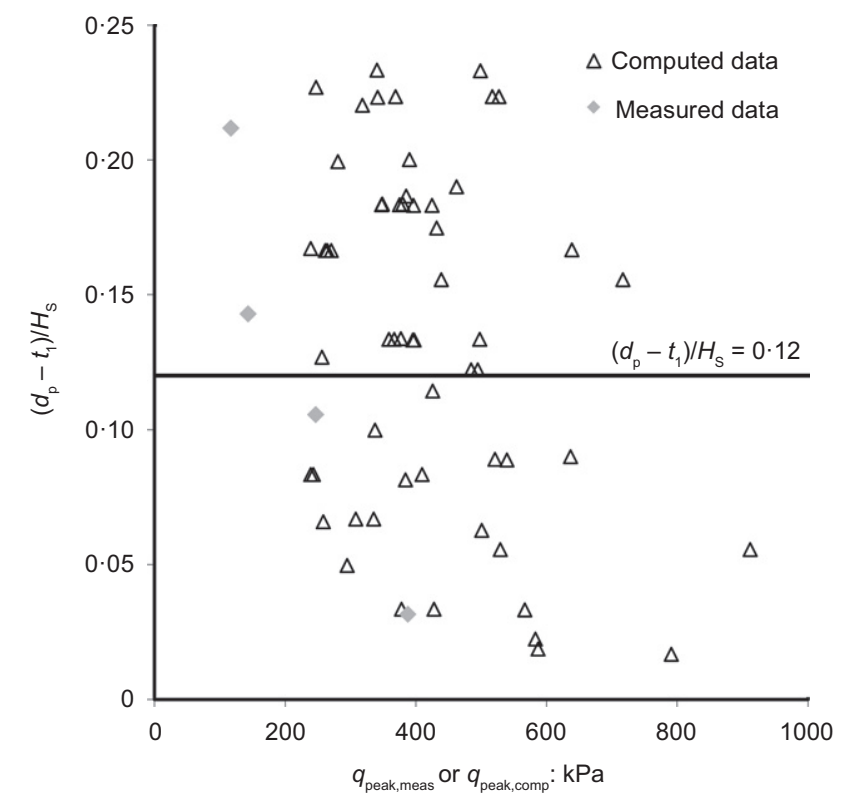

Fig. 14. Depths of peak resistance $d_{p}$ from centrifuge tests and numerical analyses

estimated peak resistance by the factor $\lambda$ (equation (11)), as shown in Fig. 15 and Table 4. For ISO methods using the proposed values of $s_{\text {ues }}$ (Fig. 15(a)), the peak resistances are estimated with the error mostly lying within $-15 \% \sim+5 \%$ of the measured and computed values. As for Lee et al. and $\mathrm{Hu}$ et al. methods with the use of $s_{\text {ues }}$ or $\lambda$ (Figs 15(b) and 15(c)), predictions of peak resistance are improved for cases with a thin third layer in which the peak resistances are overly underestimated without using the proposed improvements.

It is noted in Figs 15(b) and 15(c) that the original Lee et al. and $\mathrm{Hu}$ et al. methods tend to overestimate the computed peak resistances from the numerical analyses. This is because the methods were proposed based on centrifuge test data, while conservative peak resistances are usually given by the numerical analyses compared to the measured data (see Fig. 5).

\section{Bearing capacity in clay layer}

The penetration resistances in the clay layer that underlies the sand layer are predicted at depths of $D / 2$ and $D$ below the second-third sand-clay layer interface for cases with the absence of squeezing effect at these depths. The ratios of estimated to measured or computed values are shown in Fig. 16. Reasonable estimations are provided by the Lee et al. and $\mathrm{Hu}$ et al. methods with the error mostly less than 15\%, whereas overly conservative estimations are provided by the ISO methods due to the absence of the contribution from the soil plug.

Overall, the ratios for the Lee et al. and $\mathrm{Hu}$ et al. methods increase with increasing magnitude of measured or computed penetration resistances, with underestimation and overestimation for low-magnitude and high-magnitude resistances, respectively. This is probably due to the soil plug thickness, which diminishes gradually (at a low rate) during penetration in the clay layer, but is assumed to be constant in the calculation of Lee et al. and $\mathrm{Hu}$ et al. methods.

\section{Limiting squeezing depth}

According to the numerical analyses, the limiting squeezing depths for a clean spudcan penetrating in the first clay

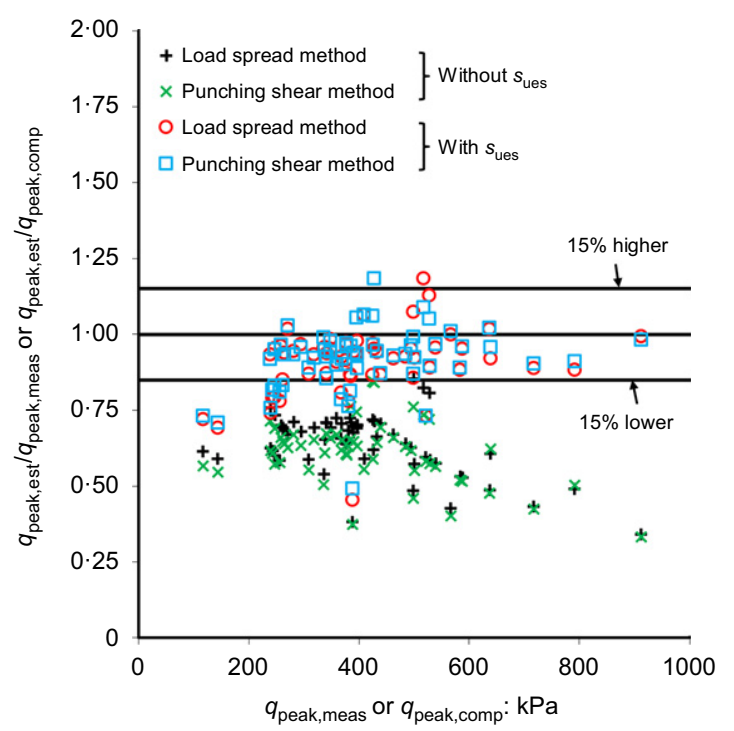

(a)

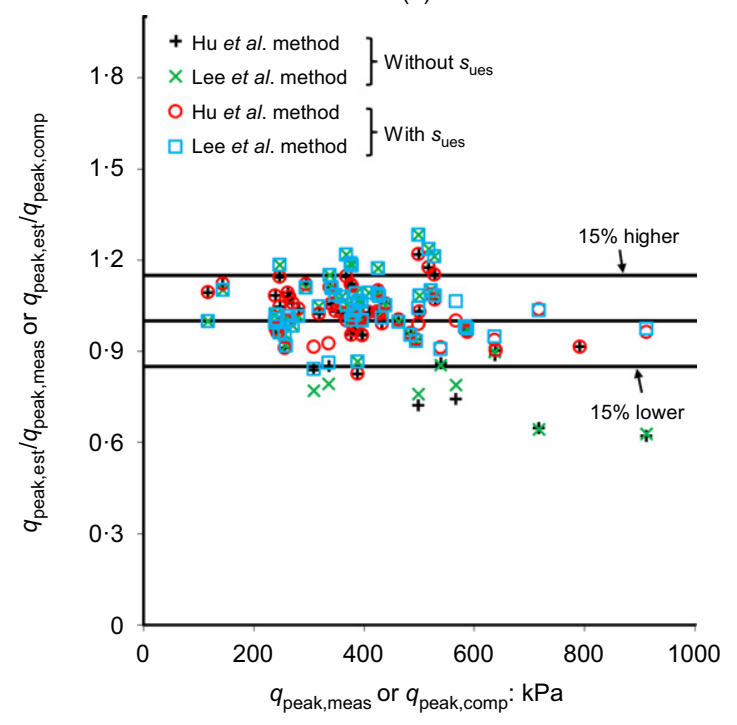

(b)

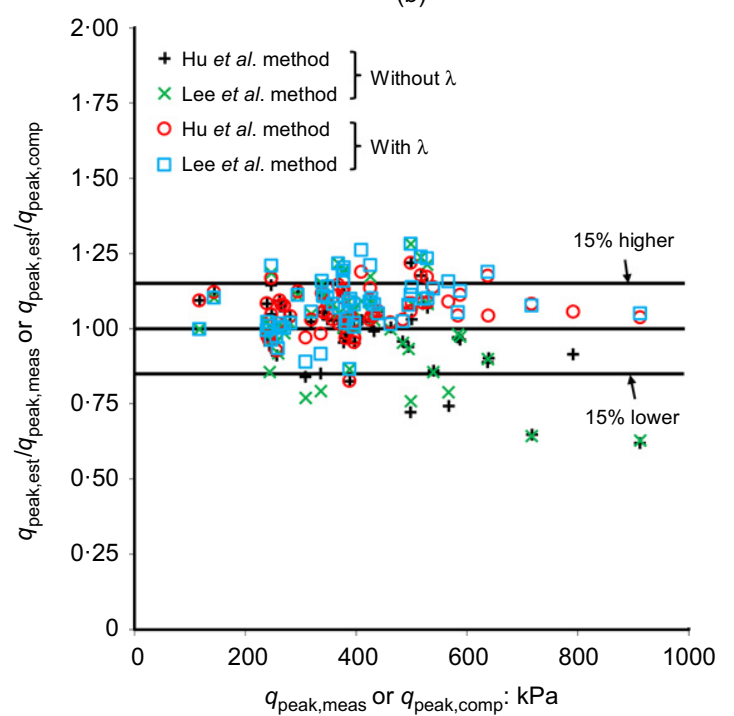

(c)

Fig. 15. Performance of design methods on estimating peak resistance: (a) ratios of estimated to measured or computed peak resistances for ISO methods with and without using $s_{\text {ues; }}$; (b) ratios of estimated to measured or computed peak resistances for Lee et al. and Hu et al. methods with and without using $s_{\text {ues; }}$ (c) ratios of estimated to measured or computed peak resistances for Lee et al. and $\mathrm{Hu}$ et al. methods with and without using $\lambda$ 
Table 4. Statistics for performance of different design methods

\begin{tabular}{|c|c|c|c|c|c|c|}
\hline \multirow[t]{2}{*}{ Ratios } & \multirow[t]{2}{*}{ Formulas } & \multirow[t]{2}{*}{ Design methods } & \multicolumn{4}{|c|}{ Statistical indices } \\
\hline & & & Min. & Max. & Mean, $\mu$ & $\mathrm{RSS}^{*}$ \\
\hline \multirow{10}{*}{$q_{\text {peak,est }} / q_{\text {peak,meas }}$ and $q_{\text {peak,est }} / q_{\text {peak,comp }}$} & \multirow[t]{4}{*}{ Original } & Load spread method & $0 \cdot 340$ & $0 \cdot 853$ & 0.638 & $8 \cdot 745$ \\
\hline & & Punching shear method & $0 \cdot 333$ & $0 \cdot 847$ & $0 \cdot 613$ & $9 \cdot 864$ \\
\hline & & Lee et al. method & 0.627 & $1 \cdot 282$ & $1 \cdot 017$ & $1 \cdot 075$ \\
\hline & & Hu et al. method & 0.620 & $1 \cdot 218$ & 0.997 & $0 \cdot 857$ \\
\hline & \multirow[t]{2}{*}{ Improved through $\lambda$} & Lee et al. method & $0 \cdot 862$ & $1 \cdot 282$ & $1 \cdot 078$ & $0 \cdot 890$ \\
\hline & & Hu et al. method & $0 \cdot 826$ & $1 \cdot 218$ & $1 \cdot 060$ & $0 \cdot 530$ \\
\hline & \multirow[t]{4}{*}{ Improved through $s_{\text {ues }}$} & Load spread method & $0 \cdot 454$ & $1 \cdot 185$ & $0 \cdot 908$ & $1 \cdot 249$ \\
\hline & & Punching shear method & $0 \cdot 492$ & $1 \cdot 184$ & $0 \cdot 916$ & $1 \cdot 130$ \\
\hline & & Lee et al. method & $0 \cdot 840$ & $1 \cdot 282$ & $1 \cdot 042$ & $0 \cdot 641$ \\
\hline & & Hu et al. method & $0 \cdot 826$ & $1 \cdot 218$ & $1 \cdot 022$ & $0 \cdot 392$ \\
\hline \multirow[t]{3}{*}{$q_{D / 2, \mathrm{est}} / q_{D / 2, \text { meas }}$ and $q_{D / 2, \mathrm{est}} / q_{D / 2, \mathrm{comp}}$} & \multirow[t]{3}{*}{ Original } & $\begin{array}{l}\text { Load spread method } \\
\text { Punching shear method }\end{array}$ & $0 \cdot 485$ & $0 \cdot 733$ & $0 \cdot 580$ & $4 \cdot 498$ \\
\hline & & Lee et al. method & $0 \cdot 743$ & $1 \cdot 126$ & $0 \cdot 910$ & $0 \cdot 417$ \\
\hline & & Hu et al. method & $0 \cdot 821$ & $1 \cdot 137$ & $0 \cdot 955$ & $0 \cdot 189$ \\
\hline \multirow[t]{3}{*}{$q_{D, \text { est }} / q_{D, \text { meas }}$ and $q_{D, \text { est }} / q_{D, \text { comp }}$} & \multirow[t]{3}{*}{ Original } & Load spread method & $0 \cdot 540$ & $0 \cdot 751$ & $0 \cdot 641$ & $2 \cdot 255$ \\
\hline & & Lee et al. method & $0 \cdot 775$ & $1 \cdot 221$ & 0.986 & $0 \cdot 285$ \\
\hline & & Hu et al. method & $0 \cdot 854$ & $1 \cdot 229$ & $1 \cdot 021$ & $0 \cdot 206$ \\
\hline
\end{tabular}

*Residual sum of squares, $\mathrm{RSS}=\Sigma\left[(\text { ratio }-1)^{2}\right]$.

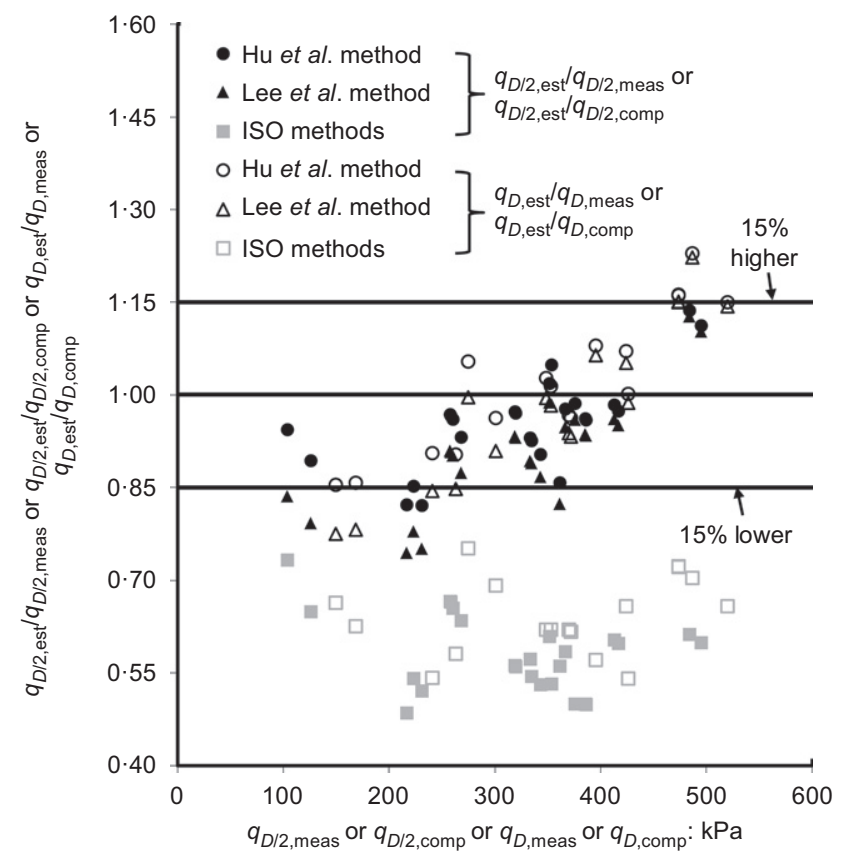

Fig. 16. Performance of design methods on estimating penetration resistance in clay

layer underlain by a sand layer range between $h_{\mathrm{sq}} / D=0 \cdot 27$ and $0 \cdot 33$, with higher $h_{\mathrm{sq}} / D$ for higher $t_{1} / D$. The corresponding estimations from the ISO recommended method (equation (3)) are $h_{\mathrm{sq}} / D=0 \cdot 23,0 \cdot 16$ and $0 \cdot 12$ for $t_{1} / D=0 \cdot 5$, 1 and $1 \cdot 5$, respectively, which are $14 \cdot 8 \sim 63 \cdot 6 \%$ lower than the computed values.

For the limiting squeezing depth in the third-layer clay with the influence of a trapped soil plug, the estimations from the ISO method (equation (3)) and the proposed iterative approach (equations (15)-(19)) are compared in Fig. 17. The ISO method always underestimates $h_{\mathrm{sq}}$ with a maximum error of $0 \cdot 89 D$. By contrast, the proposed iterative approach predicts most cases within an error of $\pm 0 \cdot 1 D$, except those with a thin clay layer of $t_{3} / D \leq 0 \cdot 5$. For $t_{3} / D>0.5$, the proposed iterative approach provides a satisfactory estimation for the limiting squeezing depth.

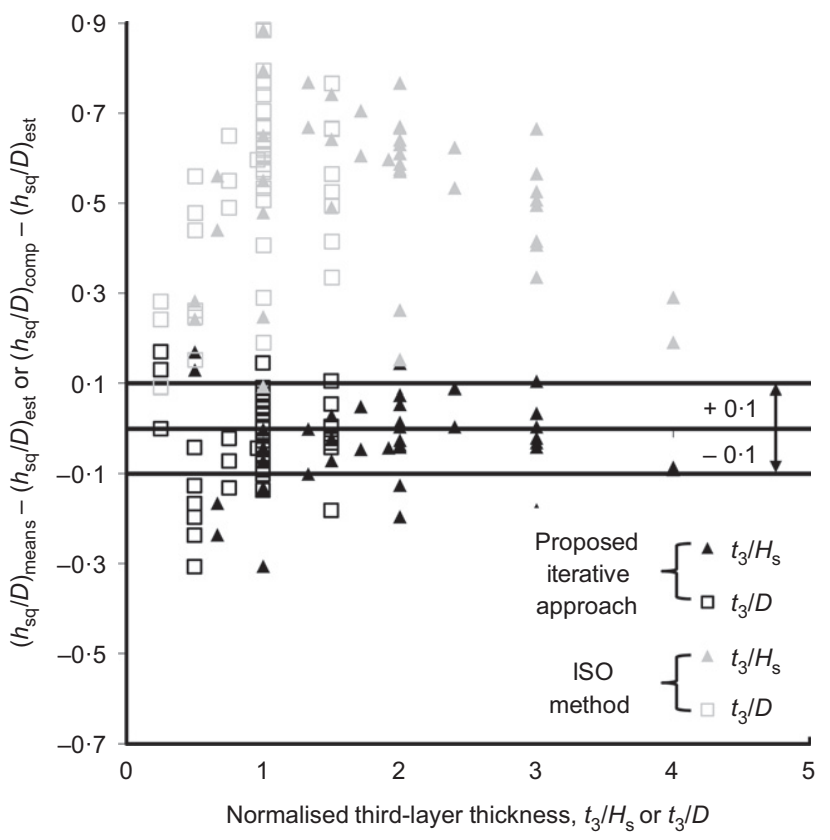

Fig. 17. Performance of proposed iterative approach and ISO-recommended method on estimating limiting squeezing depth for spudcan penetration in clay with a trapped sand plug

\section{SUMMARY OF PROPOSED DESIGN METHODS}

The design methods proposed for spudcan penetration in (a) clay-sand-clay deposits and (b) clay-sand-clay-strong layer deposits, are summarised as follows. These methods are applicable to the ranges of soil parameters (Table 2) explored in this study. For soil parameters beyond the explored ranges, caution should be exercised. The proposed methods may be applicable to $(a)$ sites where there is a fourth layer of sand instead of stiff clay, and $(b)$ sites where the first layer and third layer are relatively weaker than the second layer and fourth layer, respectively, that trigger squeezing in the first and third layers. If the first layer is very stiff (e.g. with strength $>\sim 60 \mathrm{kPa})$, the first and second layers may behave together as a strong layer, and a punch-through may trigger somewhere in these two layers. The proposed methods will 
not be applicable for this case and for four-layer deposits with the fourth layer weaker than the third layer, as noted previously.

\section{Clay-sand-clay deposit}

For spudcan penetration in three-layer clay-sand-clay deposits, the Lee et al. and $\mathrm{Hu}$ et al. methods (i.e. equations in Table 1) are extended to predict the peak resistance in the sand layer, by considering the overlying clay layer as equivalent surcharge $q_{0}$ and then taking away the submerged weight of the soils on top of the spudcan.

The load spread and punching shear methods suggested by ISO (2012) provide conservative prediction for the penetration resistance in the sand layer. For accurate prediction of the peak resistance in the sand, equivalent undrained shear strength $s_{\text {ues }}$ of the underlying clay at the sand-clay layer interface can be used in the methods, with $s_{\text {ues }}$ estimated from equation (12) and equation (13) for load spread and punching shear methods, respectively.

\section{Clay-sand-clay-strong layer deposit}

To incorporate the effect of the presence of the bottom strong layer on the peak resistance into Lee et al. and $\mathrm{Hu}$ et al. methods, two approaches can be used: $(a)$ estimate the factor $\lambda$ from equation (11) and then multiply the estimated $q_{\text {peak }}$ from the Lee et al. or $\mathrm{Hu}$ et al. method for clay-sand-clay deposit by $\lambda$; or $(b)$ use an equivalent undrained shear strength $s_{\text {ues, }}$, which can be calculated from equation (14), at the sand-clay layer interface in the formulas of the Lee et al. or Hu et al. method. For the load spread and punching shear methods, $s_{\text {ues }}$ values are estimated from equation (12) and equation (13), respectively.

To predict the depth of trigger squeezing $d_{\mathrm{sq}}$ or the limiting squeezing depth $h_{\text {sq }}$, an iterative calculation is required between equations (15) and (16), with the coefficients $f_{1}$ and $f_{2}$ estimated from equations (17)-(19).

\section{SAFETY AS OPPOSED TO ACCURACY AND ECONOMY IN DESIGN}

The safety against potential punch-through failure needs to be accounted for while predicting spudcan penetration resistance. This is why the design full preload is calculated by multiplying the actual total load by a factor of $1.5 \sim 2$ (additional preload is applied through ballasting) to ensure reserve capacity under storm events during the operation span at a site. The recent trend also emphasises enhancing the accuracy of prediction to make the design cost-effective. (Note: it is a continual process of improving ISO guidelines 19905-1 (ISO, 2012), and for instance, the recently finalised version is based on SNAME TR 5-5A Revision 2, but then the geotechnical assessment approach was revised and upgraded based on findings from industry studies and academic research projects in understanding spudcan foundation behaviour over the years; Wong et al., 2012). For example in Fig. 7(b), if it relies on the calculated penetration resistance profiles using the load spread and punching shear methods, under a full preload of maximum pressure of $\sim 310 \mathrm{kPa}$, it may be expected that the legs will experience a severe punchthrough and the required additional leg length after the punch-through depth is $\sim 2 \cdot 5 D$ (e.g. $\sim 30 \mathrm{~m}$ for $D=12 \mathrm{~m}$ ). However, the computed profiles and other mechanism-based design approaches inform that the spudcan will comfortably seat at around $0.5 \mathrm{D}$ depth, and will not experience a punch-through incident under a preload pressure of $310 \mathrm{kPa}$.

In regards to the LDFE results from this study, it is seen clearly from Fig. 5 that the computed peak resistances are either equal to or lower than the measured centrifuge test data. The underestimation is higher for a thicker sand layer. The original Lee et al. and $\mathrm{Hu}$ et al. methods are empirical methods and have been developed calibrating against measured centrifuge test data. This is why some calculated peak resistances using the extended Lee et al. and $\mathrm{Hu}$ et al. methods in Fig. 15 fall within a $0 \sim 15 \%$ overestimation of the computed peak resistances (from LDFE analyses) band. However, this does not indicate overestimation of the measured data, but rather the estimations still lie either close to or below the measured data. Nevertheless, it is routine that if the designed full preload lies on the verge (e.g. 10\% lower) of the peak resistance predicted using the extended methods, appropriate precautions and/or mitigation measures should be taken for potential punch-through.

\section{CONCLUSION}

In this paper, LDFE analyses simulating continuous spudcan penetration in clay-silica sand-clay deposits with and without a fourth-layer stiff clay have been carried out. The numerical model has been validated against centrifuge test data with reasonable agreement obtained. Parametric studies have been conducted, varying the layer geometries and strength parameters within a practical range, mainly to investigate the effect of each layer on the bearing responses in the sand layer and its underlying clay layer. Two mechanismbased design methods, the Lee et al. and $\mathrm{Hu}$ et al. methods, recently developed for spudcan penetration in surface sandover-clay deposits were extended, calibrating against LDFE results, for accurate estimation of spudcan penetration resistances in clay-sand-clay and clay-sand-clay-strong layer deposits. It has been found that for clay-sand-clay deposits, the Lee et al. and $\mathrm{Hu}$ et al. methods, overall, were capable of estimating the peak resistance in the sand layer by considering the overlying clay layer as equivalent surcharge. Design formulas have been proposed to improve the existing design methods, including ISO methods and mechanism-based methods, by quantifying the effect of the presence of a strong fourth layer on the peak resistance in the second-layer sand. An iterative approach has also been proposed to incorporate the effect of the evolving soil plug in estimating the limiting squeezing depth. Comparisons with the estimations from two ISO (2012) methods, namely, load spread and punching shear methods, confirmed the significant improvement of the accuracy.

\section{ACKNOWLEDGEMENTS}

The first author is the recipient of the University of Western Australia SIRF and UIS scholarships and the Australia-China Natural Gas Technology Partnership Fund Scholarship. The second author is an Australian Research Council (ARC) Discovery Early Career Researcher Award (DECRA) Fellow and is supported by the ARC Project DE140100903. The research presented here was undertaken with support from the Australian Research Council (ARC) through the ARC Linkage Project LP110100174. The work forms part of the activities of the Centre for Offshore Foundation Systems (COFS), currently supported as a node of the Australian Research Council Centre of Excellence for Geotechnical Science and Engineering and as a Centre of Excellence by the Lloyd's Register Foundation.

\section{NOTATION}

\footnotetext{
$A$ spudcan plan area at largest section

$D$ spudcan diameter at largest section

$D_{\mathrm{F}} \quad$ distribution factor
} 
$d$ penetration depth of spudcan base (lowest point at largest section)

$d_{\mathrm{p}}$ depth of peak penetration resistance in sand layer

$d_{\mathrm{sq}}$ depth of triggering squeezing

$E$ Young's modulus

$H_{\text {cav }}$ depth of open cavity above spudcan

$H_{\mathrm{s}}$ thickness of sand layer

$h_{\mathrm{sq}} \quad$ limiting squeezing depth

$I_{\mathrm{D}}$ relative density of sand

$I_{\mathrm{R}}$ dilatancy index

$K_{\mathrm{s}}$ punching shear coefficient

$K_{0} \quad$ coefficient of lateral earth pressure at rest

$k_{1}, k_{3}$ rate of increase of shear strength in first-, third-layer soil

$m$ dilatancy multiplier

$N_{\mathrm{c}}$ bearing capacity factor

$N_{\mathrm{c}, \text { int }}$ bearing capacity factor of spudcan at sand-clay layer interface

$n_{\mathrm{s}}$ load spread factor

$p^{\prime} \quad$ mean effective stress

$p_{0}^{\prime} \quad$ effective overburden pressure of soil at spudcan base level

$q$ deviatoric stress

$q_{D, \text { comp }}$ computed penetration resistance at $1 D$ below sand-clay layer interface

$q_{D, \text { est }} \quad$ estimated penetration resistance at $1 D$ below sand-clay layer interface

$q_{D \text {, meas }}$ measured penetration resistance at $1 D$ below sand-clay layer interface

$q_{D / 2, \text { comp }}$ computed penetration resistance at $D / 2$ below sand-clay layer interface

$q_{D / 2, \text { st }}$ estimated penetration resistance at $D / 2$ below sand-clay layer interface

$q_{D / 2, \text { meas }}$ measured penetration resistance at $D / 2$ below sand-clay layer interface

$q_{\text {peak }}$ peak resistance in sand layer

$q_{\text {peak,comp }}$ computed peak resistance in sand layer

$q_{\text {peak,est }}$ estimated peak resistance in sand layer

$q_{\text {peak,meas }}$ measured peak resistance in sand layer

$q_{\mathrm{u}}$ total bearing pressure

$q_{\mathrm{v}}$ gross bearing pressure

$S_{\mathrm{t}}$ soil sensitivity

$s_{\mathrm{u}} \quad$ intact undrained shear strength of soil

$s_{\mathrm{u}, \text { int }}$ intact undrained shear strength at sand-clay layer interface

$s_{\mathrm{u} 0} \quad$ intact undrained shear strength at spudcan base level

$s_{\mathrm{u} 1}, s_{\mathrm{u} 3}, s_{\mathrm{u} 4}$ intact undrained shear strength of first-, third-, fourth-layer soil

$s_{\mathrm{u} 1 \mathrm{~s}}, s_{\mathrm{u} 3 \mathrm{~s}}$ intact undrained shear strength of first-, third-layer soil at layer surface

$s_{\mathrm{ub}} \quad$ intact undrained shear strength of lower layer soil in two-layer system

$s_{\mathrm{uc}} \quad$ current undrained shear strength of soil accounting for strain rate and softening

$s_{\text {ues }}$ equivalent undrained shear strength at sand-clay layer interface

$T$ thickness of soil between spudcan base and layer interface in two-layer system

$t_{1}, t_{2}, t_{3}$ thickness of first-, second-, third-layer soil

$V_{\mathrm{sp}}$ volume of embedded spudcan foundation including shaft

$v$ spudcan penetration rate

$z$ depth below soil surface

$\gamma^{\prime}$ effective unit weight of soil

$r_{\mathrm{s}}^{\prime}$ effective unit weight of sand

$\gamma_{1}^{\prime}, \gamma_{2}^{\prime}, \gamma_{3}^{\prime}$ effective unit weight of first-, second-, third-layer soil $\dot{x}$ maximum shear strain rate

$\dot{\gamma}_{\text {ref }}$ reference shear strain rate at which $s_{\mathrm{u}}$ is assessed

$\Delta \boldsymbol{e}_{i j}^{\mathrm{p}} \quad$ incremental deviatoric plastic strain tensor

$\delta_{\text {rem }}^{l j}$ remoulded ratio (inverse of sensitivity)

$\varepsilon^{\mathrm{ep}} \quad$ cumulative equivalent plastic strain

$\varepsilon_{\text {crit }}^{\mathrm{ep}} \quad$ cumulative equivalent plastic strain required to achieve critical state

$\varepsilon_{\mathrm{p}}^{\mathrm{ep}} \quad$ cumulative equivalent plastic strain corresponding to peak friction angle

$\eta$ stress ratio $\lambda$ ratio between peak resistances in sand layer with and without a fourth (stiff) layer

$\mu$ rate parameter

$\xi$ accumulated absolute plastic shear strain

$\xi_{95} \quad$ softening parameter

$\sigma_{1}^{\prime}, \sigma_{2}^{\prime}, \sigma_{3}^{\prime} \quad$ effective principal stress

$\phi^{\prime}$ effective friction angle

$\phi_{\text {crit }}^{\prime} \quad$ critical state friction angle

$\phi_{\mathrm{i}}^{\prime}$ initial effective friction angle

$\phi_{\mathrm{p}}^{\prime}$ peak effective friction angle

$\psi$ dilation angle

$\psi_{\mathrm{p}}$ peak dilation angle

\section{REFERENCES}

Anastasopoulos, I., Gazetas, G., Bransby, M., Davies, M. \& El Nahas, A. (2007). Fault rupture propagation through sand: finite-element analysis and validation through centrifuge experiments. J. Geotech. Geoenviron. Engng, ASCE 133, No. 8, 943-958.

Andersen, K. H. \& Schjetne, K. (2013). Database of friction angles of sand and consolidation characteristics of sand, silt, and clay. J. Geotech. Geoenviron. Engng, ASCE 139, No. 7, 1140-1155.

Bienen, B., Qiu, G. \& Pucker, T. (2015). CPT correlation developed from numerical analysis to predict jack-up foundation penetration into sand overlying clay. Ocean Engng 108, 216-226.

Bolton, M. D. (1986). The strength and dilatancy of sands. Géotechnique 36, No. 1, 65-78, http://dx.doi.org/10.1680/geot. 1986.36.1.65.

Bolton, M. D. (1987). Discussion: the strength and dilatancy of sands. Géotechnique 37, No. 2, 219-226, http://dx.doi.org/ 10.1680/geot.1987.37.2.219.

Cheong, J. (2002). Physical testing of jack-up footings on sand subjected to torsion. Honours thesis, The University of Western Australia, Perth, Australia.

Dassault Systèmes (2010). Abaqus 6.10 online documentation. Providence, RI, USA: Dassault Systèmes, Simula Corp.

Dutta, S., Hawlader, B. \& Phillips, R. (2015). Finite element modeling of partially embedded pipelines in clay seabed using Coupled Eulerian-Lagrangian method. Can. Geotech. J. 52, No. 1, 58-72.

Einav, I. \& Randolph, M. F. (2005). Combining upper bound and strain path methods for evaluating penetration resistance. Int. J. Numer. Methods Engng 63, No. 14, 1991-2016.

Hanna, A. M. \& Meyerhof, G. G. (1980). Design charts for ultimate bearing capacity of foundations on sand overlying soft clay. Can Geotech. J. 17, No. 2, 300-303.

Hossain, M. S. (2014). Experimental investigation of spudcan penetration in multi-layer clays with interbedded sand layers. Géotechnique 64, No. 4, 258-276, http://dx.doi.org/10.1680/ geot.12.P.194.

Hossain, M. S. \& Randolph, M. F. (2009a). Effect of strain rate and strain softening on the penetration resistance of spudcan foundations on clay. Int. J. Geomech., ASCE 9, No. 3, 122-132.

Hossain, M. S. \& Randolph, M. F. (2009b). New mechanism-based design approach for spudcan foundations on single layer clay. J. Geotech. Geoenviron. Engng, ASCE 135, No. 9, 1264-1274.

Hossain, M. S. \& Randolph, M. F. (2010). Deep-penetrating spudcan foundations on layered clays: numerical analysis. Géotechnique 60, No. 3, 171-184, http://dx.doi.org/10.1680/ geot.8.P.040.

Hossain, M. S., Randolph, M. F. \& Saunier, Y. N. (2011). Spudcan deep penetration in multi-layered fine-grained soils. Int. J. Phys. Modelling Geotech. 11, No. 3, 100-115.

Hossain, M. S., Zheng, J., Menzies, D., Meyer, L. \& Randolph, M. F. (2014). Spudcan penetration analysis for case histories in clay. J. Geotech. Geoenviron. Engng, ASCE 140, No. 7, 04014034.

Houlsby, G. T. \& Martin, C. M. (2003). Undrained bearing capacity factors for conical footings on clay. Géotechnique 53, No. 5, 513-520, http://dx.doi.org/10.1680/geot.2003.53.5.513.

Hu, P., Stanier, S. A., Cassidy, M. J. \& Wang, D. (2014a). Predicting peak resistance of spudcan penetrating sand overlying clay. J. Geotech. Geoenviron. Engng, ASCE 140, No. 2, 04013009. 
Hu, P., Wang, D., Cassidy, M. J. \& Stanier, S. A. (2014b). Predicting the resistance profile of a spudcan penetrating sand overlying clay. Can. Geotech. J. 51, No. 10, 1151-1164.

Hu, P., Wang, D., Stanier, S. A. \& Cassidy, M. J. (2015). Assessing the punch-through hazard of a spudcan on sand overlying clay. Géotechnique 65, No. 11, 883-896, http://dx.doi.org/10.1680/ jgeot.14.P.097.

InSafeJIP (2011). Improved guidelines for the prediction of geotechnical performance of spudcan foundations during installation and removal of jack-up units, joint industry funded project. Woking, UK: RPS Energy.

ISO (International Organization for Standardization) (2012). ISO 19905-1: Petroleum and natural gas industries - site specific assessment of mobile offshore units - part 1: jack-ups. Geneva, Switzerland: ISO.

Jaky, J. (1944). A nyugalmi nyomas tenyezoge. Magyar Mernok es Epitesz-Egylet Kozlonye 78, No. 22, 355-358 (in Hungarian).

Lee, K. K., Cassidy, M. J. \& Randolph, M. F. (2013a). Bearing capacity on sand overlying clay soils: experimental and finite-element investigation of potential punch-through failure. Géotechnique 63, No. 15, 1271-1284, http://dx.doi.org/10.1680/ geot.12.P.175.

Lee, K. K., Randolph, M. F. \& Cassidy, M. J. (2013b). Bearing capacity on sand overlying clay soils: a simplified conceptual model. Géotechnique 63, No. 15, 1285-1297, http://dx.doi. org/10.1680/geot.12.P.176.

Low, H. E., Randolph, M. F., DeJong, J. T. \& Yafrate, N. J. (2008). Variable rate full-flow penetration tests in intact and remoulded soil. In Geotechnical and geophysical site characterization: Proceedings of the 3rd international conference on site characterization, Taipei, Taiwan (eds A.-B. Huang and P. W. Mayne), pp. 1087-1092. Leiden, the Netherlands: Taylor \& Francis Group/Balkema.

Menzies, D. \& Roper, R. (2008). Comparison of jackup rig spudcan penetration methods in clay. Proceedings of the offshore technology conference, Houston, TX, USA, paper OTC 19545.

Meyerhof, G. G. \& Chaplin, T. K. (1953). The compression and bearing capacity of cohesive layers. Br. J. Appl. Phys. 4, No. 1, 20-26.

O'Loughlin, C. \& Lehane, B. M. (2003). Measure and prediction of deformation patterns beneath strip footings in sand, Research Report No. C: 1751. Perth, Australia: Department of Civil and Resource Engineering, The University of Western Australia.

Potts, D. M., Dounias, G. T. \& Vaughan, P. R. (1990). Finite element analysis of progressive failure of Carsington embankment. Géotechnique 40, No. 1, 79-101, http://dx.doi.org/10.1680/ geot.1990.40.1.79.

Potts, D. M., Kovacevic, N. \& Vaughan, P. R. (1997). Delayed collapse of cut slopes in stiff clay. Géotechnique 47, No. 5, 953-982, http://dx.doi.org/10.1680/geot.1997.47.5.953.

Pucker, T., Bienen, B. \& Henke, S. (2013). CPT based prediction of foundation penetration in siliceous sand. Appl. Ocean Res. 41, 9-18.

Qiu, G. \& Grabe, J. (2012). Numerical investigation of bearing capacity due to spudcan penetration in sand overlying clay. Can. Geotech. J. 49, No. 12, 1393-1407.
Qiu, G. \& Henke, S. (2011). Controlled installation of spudcan foundations on loose sand overlying weak clay. Mar. Struct. 24, No. $4,528-550$.

Randolph, M. F. (2004). Characterisation of soft sediments for offshore applications. Keynote lecture. In Geotechnical and geophysical site characterization: Proceedings of the 2nd international conference on site characterisation, Porto, Portugal (eds A. Viana Da Fonseca and P. W. Mayne), vol. 1, pp. 209-231. Amsterdam, the Netherlands: IOS Press.

Skempton, A. W. (1951). The bearing capacity of clays. Proceedings of the building research congress, London, UK, vol. 1, pp. $180-189$.

Teh, K. L., Cassidy, M. J., Leung, C. F., Chow, Y. K., Randolph, M. F. \& Quah, C. K. (2008). Revealing the bearing failure mechanisms of a penetrating spudcan through sand overlying clay. Géotechnique 58, No. 10, 793-804, http://dx.doi.org/ 10.1680/geot.2008.58.10.793.

Teh, K. L., Leung, C. F., Chow, Y. K. \& Cassidy, M. J. (2010). Centrifuge model study of spudcan penetration in sand overlying clay. Géotechnique 60, No. 11, 825-842, http://dx.doi.org/ 10.1680/geot.8.P.077.

Tho, K. K., Leung, C. F., Chow, Y. K. \& Swaddiwudhipong, S. (2012). Eulerian finite-element technique for analysis of jack-up spudcan penetration. Int. J. Geomech. 12, No. 1, 64-73.

Wang, D., White, D. J. \& Randolph, M. F. (2010). Large-deformation finite element analysis of pipe penetration and large-amplitude lateral displacement. Can. Geotech. J. 47, No. 8, 842-856.

White, D. J., Teh, K. L., Leung, C. F. \& Chow, Y. K. (2008). A comparison of the bearing capacity of flat and conical circular foundations on sand. Géotechnique 58, No. 10, 781-792, http://dx.doi.org/10.1680/geot.2008.3781.

Wong, P. C., Templeton, J. S. III, Purwana, O. A., Hofstede, H., Cassidy, M. J., Hossain, M. S. \& Martin, C. M. (2012). Foundation modeling and assessment in the new ISO standard 19905-1. Proceedings of the offshore technology conference, Houston, TX, USA, paper OTC 23521.

Yapage, N., Liyanapathirana, D., Poulos, H., Kelly, R. \& Leo, C. (2015). Numerical modeling of geotextile-reinforced embankments over deep cement mixed columns incorporating strainsoftening behavior of columns. Int. J. Geomech. 15, No. 2, 04014047-1-04014047-18.

Yu, L., Hu, Y., Liu, J., Randolph, M. F. \& Kong, X. (2012). Numerical study of spudcan penetration in loose sand overlying clay. Comput. Geotech. 46, 1-12.

Zheng, J., Hossain, M. S. \& Wang, D. (2015a). Numerical modelling of spudcan deep penetration in three-layer clays. Int. J. Geomech. 15, No. 6, 04014089.

Zheng, J., Hossain, M. S. \& Wang, D. (2015b). New design approach for spudcan penetration in nonuniform clay with an interbedded stiff layer. J. Geotech. Geoenviron. Engng 141, No. 4, 04015003-1-04015003-8.

Zhou, H. \& Randolph, M. F. (2009). Resistance of full-flow penetrometers in rate-dependent and strain-softening clay. Géotechnique 59, No. 2, 79-86, http://dx.doi.org/10.1680/geot. 2007.00164 . 